Please do not remove this page

RMIT

UNIVERSITY

\title{
Biosensors based on two-dimensional MoS2
}

Kalantar Zadeh, Kourosh; Ou, Jian Zhen

https://researchrepository.rmit.edu.au/esploro/outputs/9921860385701341/filesAndLinks?institution=61RMIT_INST\&index=null

Kalantar Zadeh, K., \& Ou, J. Z. (2016). Biosensors based on two-dimensional MoS2. ACS Sensors, 1(1), 5-16. https://doi.org/10.1021/acssensors.5b00142

Document Version: Accepted Manuscript

Published Version: https://doi.org/10.1021/acssensors.5b00142

Repository homepage: https://researchrepository.rmit.edu.au

(C) 2015 American Chemical Society

Downloaded On 2023/04/26 22:04:19 +1000

Please do not remove this page 
Thank you for downloading this document from the RMIT Research Repository.

The RMIT Research Repository is an open access database showcasing the research outputs of RMIT University researchers.

RMIT Research Repository: http://researchbank.rmit.edu.au/

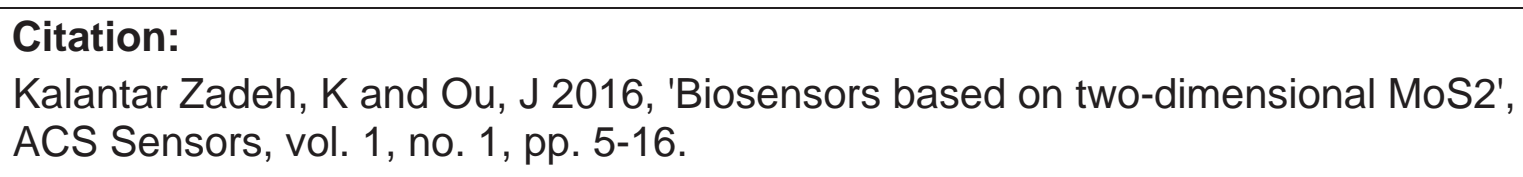

Version: Accepted Manuscript

Copyright Statement:

(C) 2015 American Chemical Society

Link to Published Version:

https://dx.doi.org/10.1021/acssensors.5b00142 


\title{
Biosensors based on Two Dimensional $\mathrm{MoS}_{2}$
}

\author{
Kourosh Kalantar-zadeh", ${ }^{1, *}$ and Jian Zhen $\mathrm{Ou}^{1}$ \\ ${ }^{1}$ RMIT University, School of Electrical and Computer Engineering, Melbourne 30o1, Australia.
}

KEYWORDS: Transition metal dichalcogenide, sensing, bio systems, intercalation, few layered, atomically thin layer, molybdenum sulfide, $2 D$

\begin{abstract}
The unique properties of two dimensional molybdenum disulfide (2D MoS2) have so far led to immense research regarding this material's fundamentals, applications and, more recently, its potentials for biosensing. $2 \mathrm{D}$ MoS2 has properties that make it of great interest for developing biosensors. These properties include large surface area, tunable energy band diagrams, a comparatively high electron mobility, photoluminescence, liquid media stability, relatively low toxicity and intercalatable morphologies. In this review, the current progress on 2D MoS2 based biosensors is presented and the prospects for future possibilities of expanding its applications for a variety of biosensing applications are discussed.
\end{abstract}

Hexagonal molybdenum disulfide $\left(2 \mathrm{H} \mathrm{MoS}_{2}\right)$ is a stratified crystal. The planes, comprising the crystal structure of $2 \mathrm{H} \mathrm{MoS}_{2}$, have thicknesses equal to the unit cell of this material that are held together by van der Waals forces. Each plane of $\mathrm{MoS}_{2}$ is made of molybdenum atoms sandwiched between sulfur atoms (Figure 1). When exfoliated into one or limited number of layers, two dimensional $\mathrm{MoS}_{2}(2 \mathrm{D} \mathrm{MoS}$ ) demonstrates unique electronic, optical, mechanical and chemical characteristics. ${ }^{1-3}{ }_{2} \mathrm{D} \mathrm{MoS}_{2}$ shows remarkable properties that also makes it advantageous for biosensing applications. ${ }^{4-5}$ When grown into planes with relatively large lateral dimensions, $2 \mathrm{D} \mathrm{MoS}_{2}$ planes are ended onto basal surfaces with no dangling bonds. As a result, these large planes are particularly stable in liquid and oxygen containing gaseous media, which facilitate their efficient incorporation into biosensing structures. ${ }^{6-7}$ In nanoflake morphology, when the surface to thickness ratio is reduced, $2 \mathrm{D} \mathrm{MoS}$ edges and corners can be engineered to either molybdenum or sulfur terminations. The molybdenum termination gives the opportunity to possibly use the metallic properties of these sites when required.

Similar to graphene and other $2 \mathrm{D}$ materials, $2 \mathrm{D} \mathrm{MoS}$ offers large surface areas that enhance its biosensing performance. However as will be discussed later, due to the existence of suitable bandgap, the overall sensitivity of devices based on $2 \mathrm{D} \mathrm{MoS}$ is much larger than graphene and graphene oxides which have either no or small bandgap. ${ }^{8}$ Many stoichiometric $2 \mathrm{D}$ oxides in comparison, have large bandgaps that require relatively high applied energy for their electronic band structure modulation. ${ }^{1}$

As $2 \mathrm{D} \mathrm{MoS}_{2}$ is atomically thin, upon interactions with a target bio material, its whole thickness is affected. ${ }^{9}$ His- torically $2 \mathrm{D} \mathrm{MoS}_{2}$ has been commonly used as a lubricating material. ${ }^{1}$ As a result, its intercalation science has experienced several decades of intensive research and therefore the relevant chemistry has been thoroughly described. In comparison to other $2 \mathrm{D}$ counterparts, only $2 \mathrm{D}$ clays have been studied to that extent for their intercalation properties. ${ }^{10}$ However, 2D clays are generally not suitable for establishing functional materials for active biosensing."

For promoting specific reactions on the surface of $2 \mathrm{D}$ $\mathrm{MoS}_{2}$ and enabling biosensing, establishing particular bonds and targeting specific biomaterials can be achieved using different functionalization methods ENREF 4 . $^{12-}$

${ }^{13}$ Inherently, the surface properties of $2 \mathrm{D} \mathrm{MoS}_{2}$ is very different to those of graphene and its oxides. $\mathrm{MoS}_{2}$ surface energy is unique and is a strong function of its sulfide deficiency. ${ }^{14}$ Functionalization of basal surfaces and sulfur ended edges of $2 \mathrm{D} \mathrm{MoS}$ can be challenging for which several methods have already been proposed, and will be briefly presented in this paper.

Various methods have been proposed for synthesizing $2 \mathrm{D} \mathrm{MoS}_{2},{ }^{3,7,15-16}$ and as such, it is always possible to find the right technique suitable for any biosensing application. Similarly, different methods have been developed for tuning electronic band structure of $2 \mathrm{D} \mathrm{MoS}_{2}$. This is in contrast to the significant challenges that are faced for modulating the electronic band structures of graphene and graphene oxides. ${ }^{17}$ The electronic energy states of $2 \mathrm{D}$ $\mathrm{MoS}_{2}$ can be adjusted ranging from semiconducting, in its intrinsic state, to fully conducting when it is transformed into the $1 \mathrm{~T} \mathrm{MoS}_{2}$ phase (with octahedral unit cells Figure 1 $\mathrm{d}$ and e) ${ }^{18}$ making this material suitable for almost many biosensing conditions. In particular, layered ${ }_{2} \mathrm{D} \mathrm{MoS}$ is 
compatible with standard electrochemical systems, which are commonly used as the working electrodes of biosensors. ${ }^{7}$ In contrast, many of the other $2 \mathrm{D}$ materials do not offer such concomitant electronic and chemical properties. $^{19}$
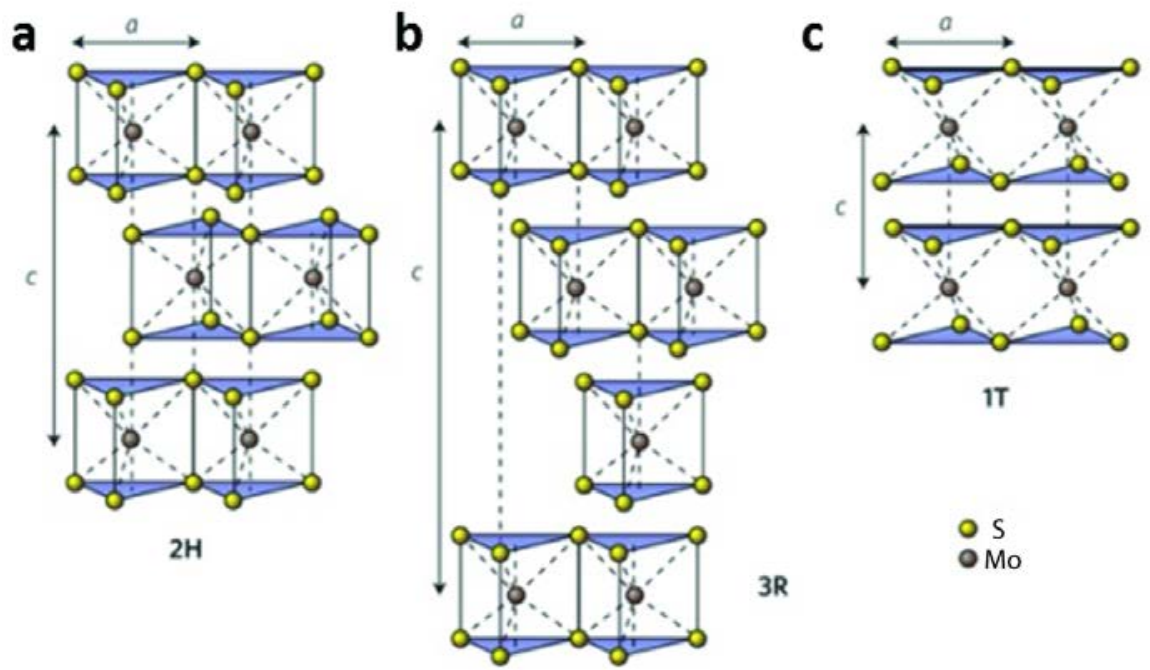

$2 \mathrm{H}$

$3 R$
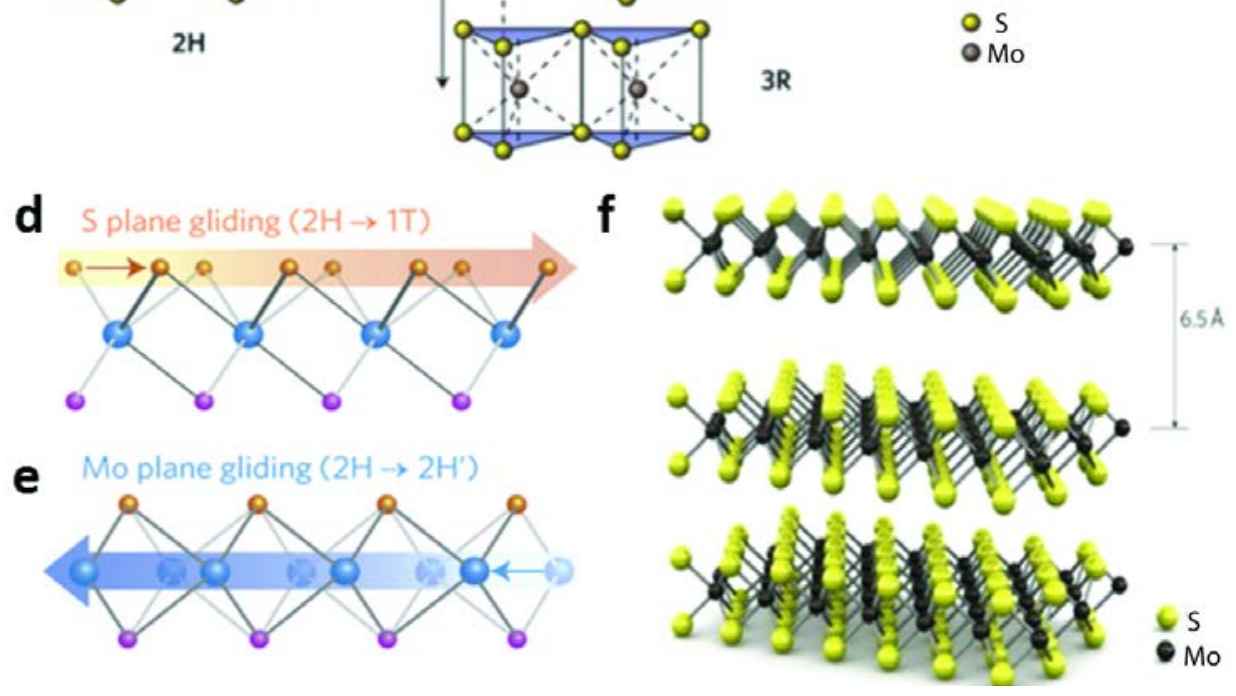

Figure 1. Schematic diagram of single-layered $\mathrm{MoS}_{2}$ of: (a) $2 \mathrm{H}$ (hexagonal symmetry, two layers per repeat unit cell, trigonal prismatic coordination). (b) ${ }_{3} \mathrm{R}$ (rhombohedral symmetry, three layers per repeat unit cell, trigonal prismatic coordination). (c) 1T (tetragonal symmetry, one layer per repeat unit cell, octahedral coordination). Figure 1a-c were reprinted with permission from Ref 3. Copyright 2012 Nature Publishing Group. (d) The S plane glides over a distance equivalent to (a = 3.16 $\AA$ ) and occupies the $\mathrm{HC}$ site of the $2 \mathrm{H}$ hexagon, which results in a $2 \mathrm{H}$ right arrow $1 \mathrm{~T}$ phase transition. (e) Gliding of the Mo plane results in a $2 \mathrm{H}$ right arrow $2 \mathrm{H}^{\prime}$ transition. Figure 1d-e were reprinted with permission from Ref 18 . Copyright 2014 Nature Publishing Group. (f) Three-dimensional representation of the structure of $\mathrm{MoS}_{2}$. Single layers, $6.5 \AA$ thick, can be extracted using scotch tapebased micromechanical cleavage. Reprinted with permission from Ref 20. Copyright 2011 Nature Publishing Group.

$2 \mathrm{D} \mathrm{MoS}_{2}$ can be easily, and at an ultrahigh capacity, intercalated via various ions ${ }^{21-22}$ and_ENREF_8 a variety of bio organic molecules that assist in establishing biosensing systems. In a one layer configuration, $2 \mathrm{D} \mathrm{MoS}_{2}$ has a direct bandgap and hence shows photoluminescence (PL), allowing the formation of optical biosensing templates. This PL that appears in the visible range can also be strongly modulated upon bio interactions and its wavelength is compatible with the low-cost standard optical systems. ${ }^{23-25}$ Such properties are only seen in a limited number of $2 \mathrm{D}$ materials. ${ }^{19}$ Additionally, $2 \mathrm{D} \mathrm{MoS}_{2}$ has highly tunable vibrational and optical characteristics, which are useful for biosensing. ${ }^{26-27}$ ENREF_9

Something that is also of interest in biosensing is the relatively low toxicity of intrinsic $2 \mathrm{D} \mathrm{MoS}_{2}$ in comparison to many other nano materials, in particular of graphene and graphene oxides. ${ }^{28}$ This is important to assure that target bio analytes are not affected in biosensing and safety measures are met. This property also allows the uptake of $2 \mathrm{D} \mathrm{MoS}_{2}$ into live cells without significantly deteriorating their viability for establishing in vivo biosensors.

Here, we present, analyze and discuss some of the major characteristics of $2 \mathrm{D} \mathrm{MoS}_{2}$ which are important for biosensing. We also describe methods for synthesizing, functionalizing and incorporating this $2 \mathrm{D}$ material into biosensors.

\section{Electronic, optical and vibrational character- istics}

The electronic band structure of $2 \mathrm{H} \mathrm{MoS}_{2}$ is strongly governed by the $d$-orbital of molybdenum. ${ }^{29}$ The four electrons from the molybdenum fill the bonding states 
around them and the surfaces of the layers are terminated by the lone-pair electrons. ${ }^{4}$ The hybridization of $d$-orbital of $2 \mathrm{H} \mathrm{MoS}_{2}$ results in the indirect-to-direct bandgap transition (Figure $2 \mathrm{a}$ and $\mathrm{b}$ ) when exfoliated into a single layer. ${ }^{26,30}$ In the bulk form of stratified $2 \mathrm{H} \mathrm{MoS}_{2}$, the conduction band minimum is located between the $\Gamma$ and $\mathrm{K}$ points, while the valence band maximum is located at the $\Gamma$ point, which constitute a bandgap of $\sim 1.29 \mathrm{eV}{ }^{31}$ Reducing the number of layers result in the upward shift of this conduction band. However as the conduction band states at the $\mathrm{K}$ point are mainly due to the $d$-orbitals of the molybdenum atoms, they remain relatively unaffected by interlayer interactions (the minimum conduction band edge is located at $\sim-4.1 \mathrm{eV}$ with reference to the vacuum). This means that the direct band gap at the $\mathrm{K}$ point only increases slightly by reducing the number of layers. This results in a direct band gap of $\sim 1.9 \mathrm{eV}$ at $\mathrm{K}$ point in one layer $\mathrm{MoS}_{2}$ (the max valence band edge is located at $6 \mathrm{eV}$ with reference to the vacuum
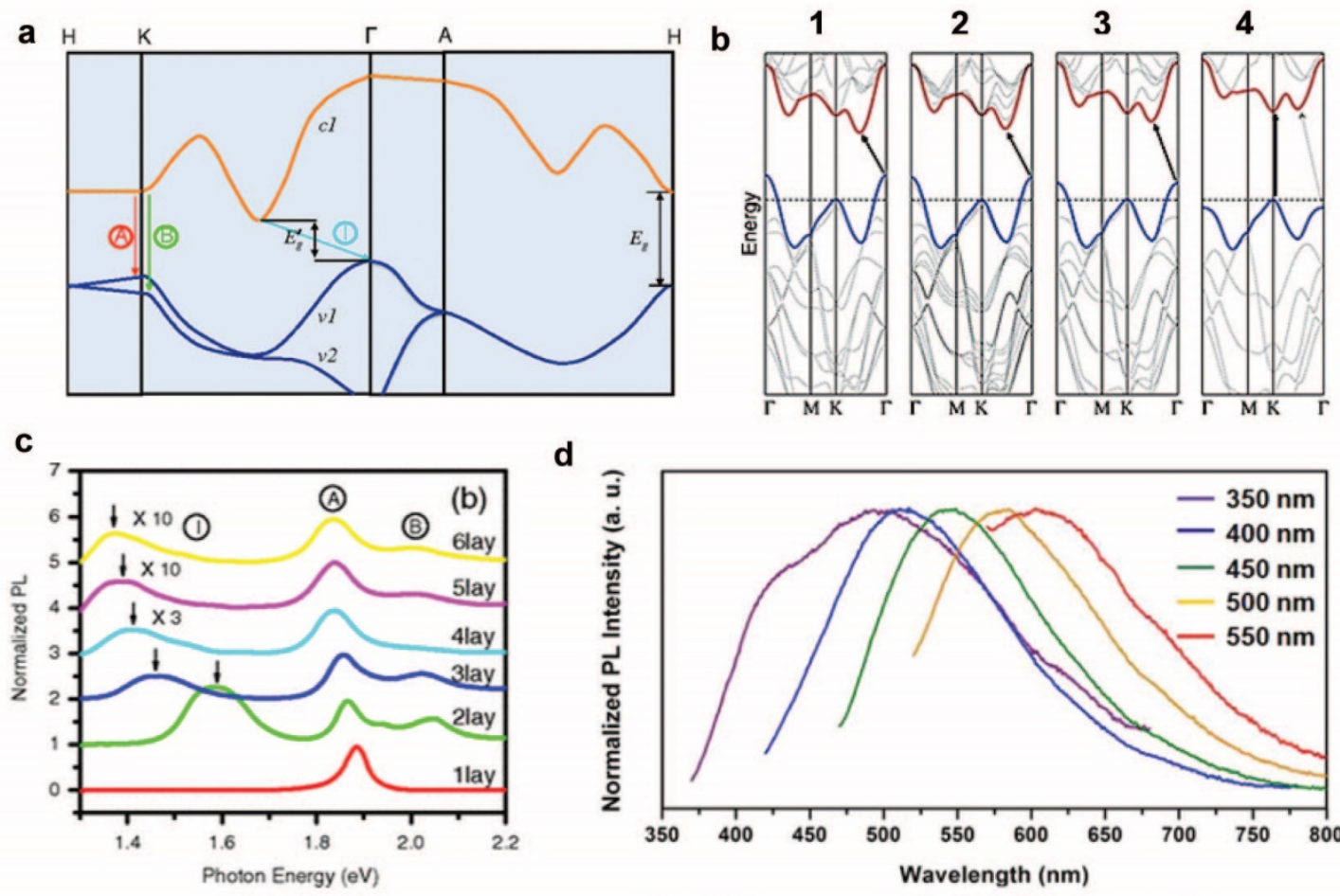

d
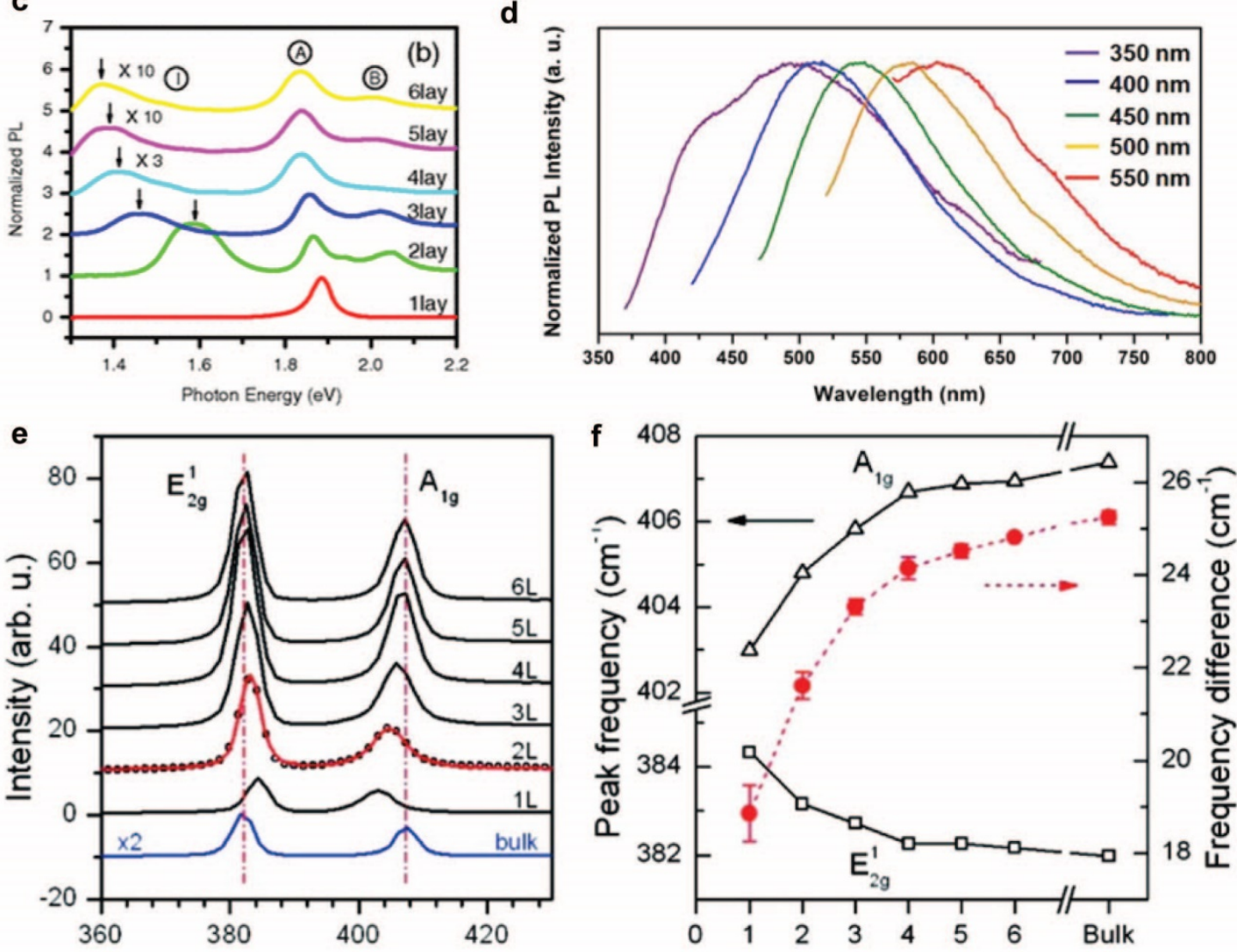

Figure 2. (a) Calculated band diagram for stratified $2 \mathrm{H} \mathrm{MoS}_{2}$ that contains both direct and indirect band gaps. Along the $\mathrm{K}$ point, the $\mathrm{A}$ and $\mathrm{B}$ excitons as well as the I peak of indirect transition are presented. (b) Calculated band structures of (1) bulk, (2) four layers, (3) two layers, and (4) monolayer $\mathrm{MoS}_{2}$. Reprinted with permission from Ref 30. Copyright 2010 American Chemical Society. (c) PL spectra of $2 \mathrm{D} \mathrm{MoS}_{2}$ planes. Figure $2 \mathrm{a}$ and c were reprinted with permission from Ref 26. Copyright 2010 American Physical Society. (d) PL spectra of suspended quasi-2D MoS 2 nanoflakes at different excitation wavelengths (350, 400, 450, 500, and $550 \mathrm{~nm}$ ). Reprinted with permission from Ref 21. Copyright 2014 American Chemical Society. (e) Raman spectra of a few layered and bulk $\mathrm{MoS}_{2}$. (f) Peak positions of $\mathrm{E}_{2 \mathrm{~g}}^{1}$ and $\mathrm{A}_{1 \mathrm{~g}}$ Raman modes and their difference as a function of layer thickness. Figure ze-f were reprinted with permission from Ref 5 . Copyright 2010 American Chemical Society. 
It has been shown that one layer $\mathrm{MoS}_{2}$ is able to offer the on/off ratio of $>10^{8}$ when incorporated into field effect transistor configurations. ${ }^{20}$ This large value is certainly advantageous in establishing biosensors, as any slight change in the electron channel area can be efficiently used for forming highly sensitive biosensors. The effective mass of electrons at the $\mathrm{K}$ point of $2 \mathrm{D}$ in $\mathrm{MoS}_{2}$ has been estimated as $0.48 \mathrm{~m}_{\mathrm{e}} \cdot{ }^{31-32}$ The free carrier scattering in $2 \mathrm{D}$ $\mathrm{MoS}_{2}$ is dominated by their interactions with acoustic phonons at temperatures lower than $100 \mathrm{~K}$ and optical phonons above such temperatures. ${ }^{32}$ The highest free carrier mobility has been estimated $\sim 400 \mathrm{~cm}^{2} / \mathrm{Vs}$ at room temperature. In reality, gaining such free carrier mobilities without high permittivity layers is not possible. A carrier lifetime of $\sim 100$ ps and diffusion coefficient of $\sim 20$ $\mathrm{cm}^{2} / \mathrm{s}$ have been shown for $2 \mathrm{D} \mathrm{MoS} .{ }^{33}$ Both carrier lifetime and diffusion coefficient are suitable numbers to establish field effect and electrochemical based biosensors.

$2 \mathrm{D} \mathrm{MoS}_{2}$ electronic band structure characteristics give rise to certain excitonic and fluorescent properties that can be efficiently used for biosensing. $2 \mathrm{D} \mathrm{MoS}_{2} \mathrm{PL}$ spectrum shows two exciton peaks of $\mathrm{A}(\sim 1.92 \mathrm{eV})$ and $\mathrm{B}$ $(\sim 2.08 \mathrm{eV})$ at the $\mathrm{K}$ point (Figure $2 \mathrm{a}-\mathrm{c}){ }^{26,}{ }^{30}$ These peaks are suggested to appear due to valence band spin orbit splitting by $\sim 145 \mathrm{meV} .{ }^{34}$ Two extra exciton peaks of $\mathrm{C}$ and $\mathrm{D}$ also exist. The introduction of excess electrons causes a split of the exciton A peak, which is associated to the emergence of negative trions of high binding energies. ${ }^{26}$ Interestingly, this splitting occurs at room temperature which is also significant for optical biosensing observations. The existence of PL can be specially designed fluorescence tagging as a possibility for surveillance, tracing and sensing of biological components. $2 \mathrm{D} \mathrm{MoS}_{2}$ can also be successfully bound to other fluorophores. Specially functionalized $2 \mathrm{D} \mathrm{MoS}_{2}$ with relatively small lateral dimensions, which can be uptaken by cells, can be applied for bio imaging and consequently biosensing using a variety of conventional and near field optical microscopy techniques (Figure $2 \mathrm{~d}$ ). ${ }^{35}$

2D $\mathrm{MoS}_{2}$ shows strong vibrational characteristics. This material has four Raman-active modes $\left(E_{1 g}, E_{2 g}^{1}, A_{1 g}\right.$, and $\left.\mathrm{E}^{2}{ }_{2 \mathrm{~g}}\right)$. It also demonstrates two IR-active modes $\left(\mathrm{A}_{2 \mathrm{u}}\right.$ and $\left.E_{1 \mathrm{u}}\right) .^{36-37} \mathrm{E}_{2 \mathrm{~g}}$ is an in-plane mode, attributed to the opposite vibration of two $S$ atoms with respect to Mo, and $A_{19}$ mode is in an out-of-plane vibration of only $S$ atoms in opposite directions. Reducing the number of layers result in the red and blue shifts of $E_{2 g}^{1}$ and $A_{1 g}$ modes, respectively (Figure 2 e and $\mathrm{f}$ ). ${ }^{5}$ Due to its out-of-plane nature, the $A_{1 g}$ mode is very sensitive to adsorbates on the $\mathrm{MoS}_{2}$ surface and charge exchanges. ${ }^{38}$ The Raman and IR active modes are also function of lateral dimensions, permittivity of the environment, defects and intercalation properties. As such, observations and investigations of the vibrational modes are suitable for a variety of biosensing applications via Raman and FTIR spectroscopies. ${ }^{27}$

\section{Synthesis techniques}

Methods for synthesizing $2 \mathrm{D} \mathrm{MoS}_{2}$ compromise a wide range, including those that exfoliate thin layers from bulk $2 \mathrm{H} \mathrm{MoS}_{2}$ or others that vapor/liquid phase deposit the single layers of $\mathrm{MoS}_{2}$ directly on a substrate.

Similar to graphene, some of the most common approaches for obtaining $2 \mathrm{D} \mathrm{MoS}_{2}$ are still based on mechanical exfoliation using adhesion tapes. ${ }^{39}$ Such methods generally result in the highest-quality monolayers of $\mathrm{MoS}_{2}$ on any arbitrary substrate. ${ }^{40}$ However, low yield and random landing of the $2 \mathrm{D} \mathrm{MoS}_{2}$ flakes on substrates are problematic, especially for large scale production. ${ }^{3}$ Mechanical exfoliation methods are particularly useful for establishing field effect based biosensors.

A variety of gas/vapor chemical deposition methods have been developed for wafer scale growth of $2 \mathrm{D} \mathrm{MoS}{ }^{4{ }^{4-}}$ ${ }^{43}$ Many of these techniques result in $2 \mathrm{D} \mathrm{MoS}_{2}$ in triangular morphologies with side dimensions as large as several hundreds of $\mu \mathrm{m} .{ }^{41}$ The chemical deposition methods generally start with forming a very thin layer of organic/inorganic precursor of $2 \mathrm{D} \mathrm{MoS}_{2}$ followed by a series of annealing and sulfurization steps. ${ }^{43-44}$ Ammonium tetrathiomolybdate and molybdenum oxides are amongst the common precursors which are used in one or twostep deposition/annealing processes. ${ }^{41}$ The sulfurization step is generally conducted above $500{ }^{\circ} \mathrm{C}$ using $\mathrm{H}_{2} \mathrm{~S}$ gas or sulfur vapor. ${ }^{41}$ The current challenge is to obtain wafer scale high quality and homogenous $2 \mathrm{D} \mathrm{MoS}_{2}$ layer. The crystallinity and other qualities of the substrate play an important role is the success of the deposition process. While substrates such as sapphire yield the best outcomes, $\mathrm{SiO}_{2}$ covered $\mathrm{Si}$ wafers as well as silica glass or conductive glass substrates are the most on demand bases for developing biosensors. ${ }^{8,45-46}$

Liquid exfoliation techniques are suitable for obtaining suspensions of $2 \mathrm{D} \mathrm{MoS}$. These suspensions are particularly useful for optical and vibrational biosensing applications, which are compatible with microfluidic systems. ${ }^{47}$ Some of the most high yielding liquid exfoliation methods are based on lithium intercalation techniques. ${ }^{48}$ However, these processes are generally hazardous and require long durations. Microwave assisted processes have been proposed to reduce the reaction time. ${ }^{49}$ Lithiation can also be electrochemically implemented but it limits the yield. ${ }^{50}$ Such processes generally need refluxing to remove the ionic residues in order to make the final product suitable for biosensing applications.

There are also liquid exfoliation methods which are based on high power sonication with the assistance of materials that enhance physical surface adhesion on stratified $\mathrm{MoS}_{2}$. Colman et al have proposed liquid exfoliation methods based on shear force effects, ${ }^{51-53}$ which are assisted by surfactants or organic solvents. Advantageously, these methods can be readily used in forming $2 \mathrm{D} \mathrm{MoS}_{2}$ suspensions in organic solvents compatible with biosensing processes. However, such liquid phase processes still leave residues on $2 \mathrm{D}$ flakes. Several centrifuge steps can assist in removing the remnants. Also hexane treatment 
and annealing at optimum temperatures can help. ${ }^{35} \mathrm{Ob}-$ taining a clean surface is especially important for biosensing in which specific fuctionalizations are required to make the surface more specific to any specific target bio analyte.

The readers are referred to other review papers ${ }^{1,3}$ for more information on the synthesis of $2 \mathrm{D} \mathrm{MoS}$.

\section{Functionalization}

For the development of biosensors, after the synthesis of $2 \mathrm{D} \mathrm{MoS}$, these thin sheets should be functionalized to respond to specific bio targets. Surface functionalization result in charge displacement and formation of surface dipoles that can cause dramatic effects on the electronic band structures of $2 \mathrm{D} \mathrm{MoS}_{2} .{ }^{54}$ There are already many reports on the functionalization of basal surface of $2 \mathrm{D}$ $\mathrm{MoS}_{2}$ via standard surface methods. In practice, many of those reports are incorrect as not paying attention that no dangling bonds and very large surface of $\mathrm{MoS}_{2}$ with van der Waals affinity promote physisorption. It means that molecules tend to lie flat on the surface of $\mathrm{MoS}_{2}$ rather than establishing covalent or strong ionic bonds. Such physisorption reactions seem to have a very low selectivity in nature. However, if they are used intelligently, the physisorbed layer onto $\mathrm{MoS}_{2}$ can be engineered to form the base an assay that results in a high selectivity surface for a particular target bio analyte.

It has been suggested that basal planes of $\mathrm{MoS}_{2}$ can be functionalized using silane and thiol based methods, which are commonly applied for modifying oxide and chalcogenides surfaces. ${ }^{55^{-56}}$ Such methods strongly rely on the formation of hydroxyl of thiol groups on the surface. In an ideal world, there is no dangling bond on the basal surface of $\mathrm{MoS}_{2}$ and such groups can only efficiently adhere onto molybdenum, emerging from disrupted sulfur bonds. This means that effective surface functionalizations via those methods depend on the presence of sulfur deficiencies. The edges of $2 \mathrm{D} \mathrm{MoS}$ flakes are either terminated by metal or chalcogen atoms, depending on conditions of synthesis. ${ }^{29}$ In addition, low-coordination stepedges and kinks can also be formed that induce altered local surface effects/energies. ${ }^{57}$ Generally reducing the lateral dimensions of $2 \mathrm{D} \mathrm{MoS}_{2}$ flakes encourage the domination of such properties. The missing coordination at the edges, steps and kinks give rise to metallic states that can be used for incorporating functional groups, including hydroxyls and thiols. ${ }^{58}$ Alternative methods can also be used. Disulfide bonds in the form of R-S-S-C can be established by coupling of two thiol groups for immobilizing organic entities such as various proteins. Acid compounds containing -SOH groups can also bind to proteins and carbohydrates and partially act as catalysts or intermediates for bio interactions.

Many other methods such as in situ reduction of metal ions, esterfication, ring-opening polymerization and free radical polymerization can also be used. There are also more recent reports on covalently bond amide and methyl moieties onto sulfur-based metallic $1 \mathrm{~T} \mathrm{MoS}_{2} \cdot{ }^{59}$ Very interestingly, a change from metallic $1 \mathrm{~T}$ to semiconducting $2 \mathrm{H}$ was observed after this procedure.

Functionalizations also play important roles in stabilizing $2 \mathrm{D} \mathrm{MoS}_{2}$ in ionic solutions by reducing the nonspecific dangling bonds. Ionic solutions such as phosphate buffer salines are the base of biosensing, ${ }^{60-61}$ as such stable suspensions of $2 \mathrm{D} \mathrm{MoS}_{2}$ are critical.

It is important to consider that $2 \mathrm{D} \mathrm{MoS}_{2}$ is a stable materials in photo activated reactions. ${ }^{62}$ As such many optical grafting technologies can be implemented for functionalization of the surface of $\mathrm{MoS}_{2}$ without deteriorating its properties.

\section{Catalysis}

Enhancing the catalytic performance of $2 \mathrm{D} \mathrm{MoS}_{2}$ surface is an important property for augmenting bio reactions and also longevity of biosensors (surface poisoning). Catalytic strength of intrinsic $2 \mathrm{D} \mathrm{MoS}_{2}$ is not as large as metallic materials, but advantageously shows strong resistance to poisoning. ${ }^{63}{ }_{2} \mathrm{D} \mathrm{MoS}_{2}$ catalytic properties can be based on either dark electron transfer (hydrogenation reaction) or photochemical processes or a simultaneous combination of both. It is suggested that the rim sites of ${ }_{2} \mathrm{D} \mathrm{MoS}_{2}$ predominately cause the hydrogenation, while the metallic edges catalyze organic entities. ${ }^{48}$

\section{Intercalation}

${ }_{2} \mathrm{D} \mathrm{MoS}_{2}$ is a popular material for $\mathrm{H}^{+}$and $\mathrm{Li}^{+}$intercalation as an efficient base for energy storage. ${ }^{64-65}$ Intercalation is also potentially an important process in $\mathrm{MoS}_{2}$ based biosensors. ${ }^{66}$ When bio targets are brought into the vicinity of $2 \mathrm{D} \mathrm{MoS}_{2}$ (made of more than two layers), a portion of these materials are adsorbed onto the surface and the rest can be intercalated (reversibly included into the layered crystal). ${ }^{48}$ The competition between the surface adsorption and intercalation depend on the type and intensity of the applied energy. It also depends on the nature of adsorbates/intercalants and their surface energies with respect to the surface and interlayer binding energies of $2 \mathrm{D} \mathrm{MoS}$.

Particles can be incorporated within the interlayer spacings through direct intercalation ${ }^{48}$ and exfoliationrestacking. ${ }^{48,55}$ The intercalation processes of $\mathrm{MoS}_{2}$ are generally topotactic, in which interlaminar distances change. The interlayer expansion measurements can provide relevant information regarding the nature of inserted phase. Intercalation may induce drastic changes in the electronics, optics and transport properties of $2 \mathrm{D} \mathrm{MoS}_{2}$. Engineering of these properties is potentially beneficial for biosensing.

There are many reports on processes for the intercalation of ionic and organic entities into $\mathrm{MoS}_{2}{ }^{22,}$ 49, 67-68 However, interaction of biological components, such as amino acids and DNA strands, frequently appearing in biosensing processes yet to be reported. 


\section{Toxicity and cell labeling}

In general, toxicity can be an important issue for biosensing. While toxicity does not seem to have a direct impact on sensing organic analytes, low toxicity is important for keeping the viability of cells under biosensing investigations. $2 \mathrm{D} \mathrm{MoS}$ is both itself fluorescence and can also be successfully adhered to fluorophores. As a result, it can be used for tagging and imaging different cell organs. ${ }^{4}{ }^{6}{ }_{2} \mathrm{D} \mathrm{MoS}_{2}$ flakes with small lateral dimensions can be uptaken by live cells and used in high contrast celltargeted labeling for biosensing and imaging applications (Figure 3$).^{70}$

a

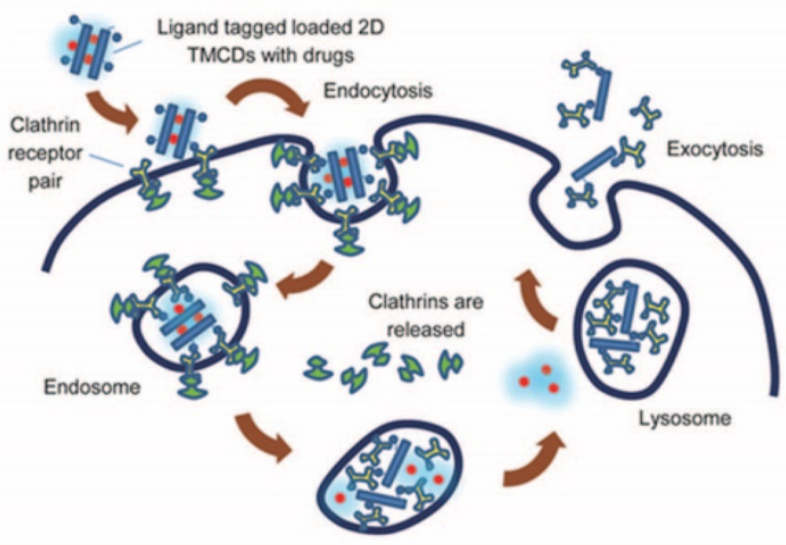

b

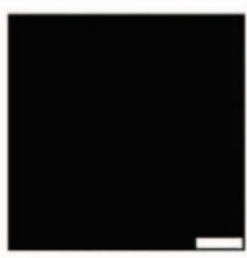

$0 \mu \mathrm{M} \mathrm{Ag}^{+}$
$20 \mu \mathrm{M} \mathrm{Ag}^{+}$

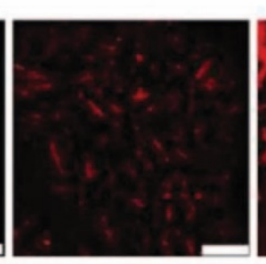

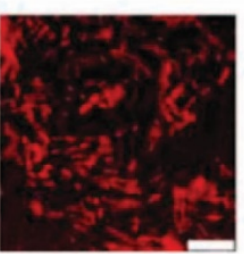

$50 \mu \mathrm{M} \mathrm{Ag}^{+}$
Figure 3. (a) Schematic illustrations of layered $2 \mathrm{D} \mathrm{MoS}$ flake uptake and drug delivery concept: layered ${ }_{2} \mathrm{D} \mathrm{MoS}$ is loaded with drugs (or fluorophores) and conjugated with a ligand allowing cellular uptake. The ligand on the $2 \mathrm{D} \mathrm{MoS}_{2}$ anchors to the receptor-clathrin pair facilitating clathrinmediated endocytosis. The loaded $2 \mathrm{D} \mathrm{MoS}_{2}$ enters the cell within a vesicle. It may stain special cell organelles or in later stages transport and release a drug. Reprinted with permission from Ref 4. Copyright 2015 John Wiley \& Sons Publishing Company. (b) Confocal fluorescence microscopy of E. coli stained with $\mathrm{MoS}_{2}$ - rhodamine $\mathrm{B}$ isothiocyanate (RhoBS) nanoprobes. E. coli were cultured with o, 20 and $50 \mu \mathrm{M} \mathrm{Ag}^{+}$ions and added to $\mathrm{MoS}_{2}-\mathrm{RhoBS}$ before imaging. Scale bar $=7.5$ $\mu \mathrm{m}$. Reprinted with permission from Ref ${ }^{69}$. Copyright 2015 American Chemical Society.

It is commonly believed that multi layered $\mathrm{MoS}_{2}$ has a low toxicity. However, depending on exfoliation parameters, defect density and chemical compositions, the toxicity of $2 \mathrm{D} \mathrm{MoS}_{2}$ alters. The investigations of toxicity of fewlayered $\mathrm{MoS}_{2}$ by in vitro colorimetric assays for a cell viability have found that it shows low toxicity profile towards lung cancer cells. ${ }^{28}$ It has been demonstrated that by decreasing the number of layers in $2 \mathrm{D} \mathrm{MoS}$, the toxicity increases, which is attributed to the enhanced surface area, defects and edges. ${ }^{71}$ When testing toxicity of nanomaterials, one shall exercise caution as the nanomaterial may also interact with viability of markers in assays. ${ }^{28}$ Still more studies should be conducted to understand the differences between the toxicity of $1 \mathrm{~T}$ and $2 \mathrm{H}$ (metallic and semiconducting, respectively) $2 \mathrm{D} \mathrm{MoS}_{2}$ as well as the effect of defects, kinks and edges.

\section{Biosensors}

${ }_{2} \mathrm{D} \mathrm{MoS}_{2}$ is increasingly becoming a popular material for biosensing applications and a significant number of publications have emerged regarding its incorporation into biosensors in recent years. As already discussed in detail, this material's high surface-to-volume ratio and layered structure can accommodate large capacity of chemical/bio species. $2 \mathrm{D} \mathrm{MoS}_{2}$ has functionalization diversity, desirable optical and electronic properties as well as unique vibrational characterizations and shows certain advantages for establishing biosensors. ${ }^{4,72-74}$

Current biosensors based on $2 \mathrm{DMoS}_{2}$ can be categorized into several types including electrode based devices, electrodeless optical systems and reverse electro luminescent systems, which are discussed in the following sections.

\section{Electrode based biosensors}

Relying on the incorporation of electrodes, one category of $2 \mathrm{D} \mathrm{MoS}$ biosensors is based on field effect transducing platforms. Such devices relate the changes of charge or mass, on the surface of $2 \mathrm{D} \mathrm{MoS}$, to the changes in the size and area of the underneath resistive channel and hence transconductance changes. ${ }^{8}$ The added charge (ionic entities or electron transfer) on the surface can also change the threshold voltage of the device for which an adaptation of the Nernst equation maybe implemented for assessing the concentration of the target analyte. Field effect based sensors using $2 \mathrm{D} \mathrm{MoS}_{2}$ have been shown for label free biosensing and employed for sensing proteins, DNA and other biochemical components. ${ }^{8,45-46}$ A representation of such biosensors is shown in Figure 4 $\mathrm{a}-\mathrm{d}$, in which $2 \mathrm{D} \mathrm{MoS}_{2}$ is placed between drain and source electrodes. Sarkar et al have shown the impressive sensitivity of the $2 \mathrm{D} \mathrm{MoS}_{2}$ based biosensors that stems from their suitable bandgap and high on/off ratio as field effect templates (Figure $4 \mathrm{e}-\mathrm{i}){ }^{8}$

They demonstrated ultrasensitive, and specific to selected proteins, biosensing with a sensitivity exceeding 200 even at femtomolar concentrations. In comparison to graphene based devices, their $2 \mathrm{D} \mathrm{MoS}$ based field effect biosensor showed an impressive $\sim 75$ fold better response. Additionally, their $2 \mathrm{D} \mathrm{MoS}_{2}$ based field effect $\mathrm{pH}$ sensor also achieved a sensitivity of $>700$ for a $\mathrm{pH}$ change by one unit. $^{8}$

In field effect biosensors, very often a reference electrode, such as $\mathrm{Ag} / \mathrm{AgCl}$ type, is used as the suspended 
gate. The application of the reference electrode can be particularly important as it helps the formation of a double electrical layer on the surface of the $2 \mathrm{D} \mathrm{MoS}_{2}$ channel that assists the fast and efficient formation of ionic species on the channel surface, hence reducing the response time and sensitivity. Presence of a top or back gate voltage can also be helpful to assure that the transistor is biased into switched on mode during biosensing. ${ }^{75}$ The bias can assist in forming the electrical double layer in order to reduce the need for a suspended reference electrode. A discussion on differences between the top and back gate biasing for biosensing can be found in the work of Nam et $a l^{76}$

Functionalization of $2 \mathrm{D} \mathrm{MoS}_{2}$ is very important to achieve the selectivity and sensitivity needed for field effect biosensing. Lee et $a l^{75}$ used prostate specific antigens to obtain pico levels of sensitivities without a reference electrode. They also obtained single stranded DNA detection limit of 10 femto moles at $17 \mathrm{mV}$ change for each orders of magnitude of concentration change. ${ }^{77} \mathrm{Nam}$ et $a l^{78}$ investigated an anti-human antibody for detecting specific proteins in femto molar ranges of the response time of 10 mins or more, depending on the concentration.
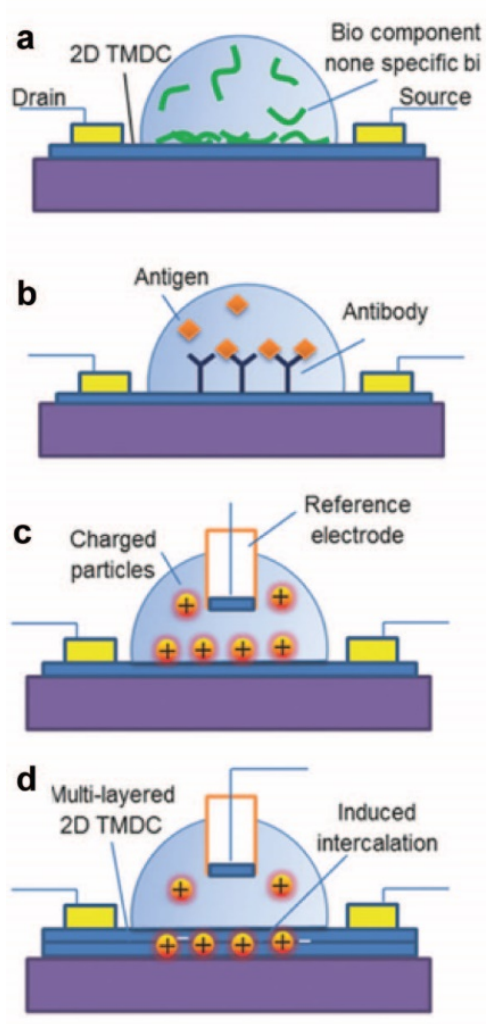
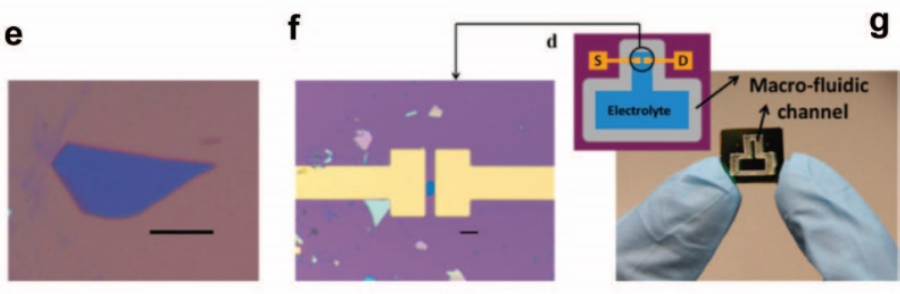

h
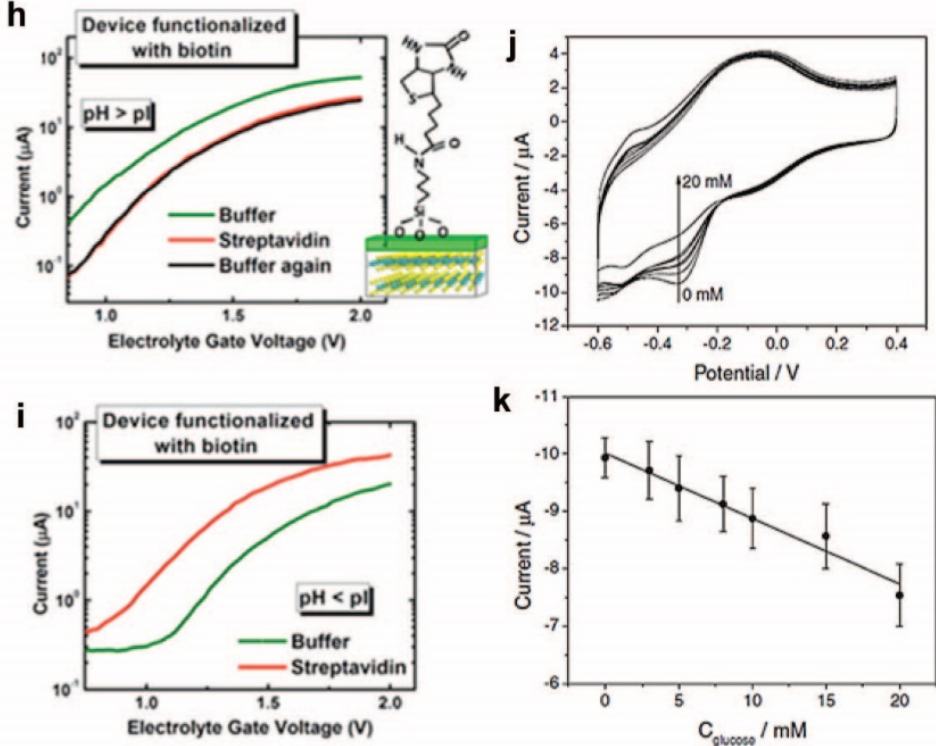

Figure 4. $2 \mathrm{D} \mathrm{MoS}_{2}$ based field effect biosensors in response to adsorbates according to: (a) Non-specific binding, (b) Lock and key concept (antibody-antigen interaction in this example), (c) With a reference electrode to produce the electrical double layer and (d) With a reference electrode, and multiple layer $2 \mathrm{D} \mathrm{MoS}$, to induce intercalation. Reprinted with permission from Ref 4.

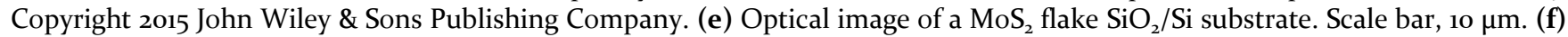
Optical image of the $\mathrm{MoS}_{2}$ field effect biosensor. Scale bar, $10 \mu \mathrm{m}$. (g) Image and schematic diagram (inset figure) of the chip with the biosensor device and microfluidics. (h) Output characteristics of $2 \mathrm{D} \mathrm{MoS}_{2}$ field effect based biosensors functionalized with biotin: first measured in phosphate buffer. Addition of streptavidin solution (1o $\mu \mathrm{M})$ leads to decrease in current due to the negative charge of the protein, as the $\mathrm{pH}$ of the solution is more than the isoelectric point of streptavidin. The device is then measured again in pure buffer, leading to no significant change. (i) The same device after the addition of streptavidin solution $(10 \mu \mathrm{M})$ at a $\mathrm{pH}$ of 4.75 , which is less than the isoelectric point of streptavidin, leading to an increase in current consistent with the positive charge of the protein. Figure 4e-i were reprinted with permission from Ref 8. Copyright 2014 American Chemical Society. (j) Cyclic voltammograms of different concentrations of glucose (o, 3, 5, 8, 10, 15, and $20 \mathrm{mM})$ onto $\mathrm{MoS}_{2}$-chitosanglucose oxidase electrodes at the scan rate of $50 \mathrm{mVs}^{-1}$ and $(\mathbf{k})$ its corresponding calibration curve. Figure $4 \mathrm{j}-\mathrm{k}$ were reprinted with permission from Ref 7. Copyright 2012 John Wiley \& Sons Publishing Company.

Other type of commonly used $2 \mathrm{D} \mathrm{MoS}_{2}$ based biosensors, which rely on electrodes, are electrochemical types. They are designed to sense bio related ionic species generated in redox reactions, in a procedure that is promoted by the electric field from a reference electrode. In these systems, the working electrode is covered with $2 \mathrm{D} \mathrm{MoS}_{2}$ and the reference electrode is generally the $\mathrm{Ag} / \mathrm{AgCl}$ type. A counter electrode is also commonly used in such systems that help in separating the applications and measurements of the applied voltage and current. Wu et al ${ }^{7}$ 
presented one of the first reports of such sensors for $2 \mathrm{D}$ $\mathrm{MoS}_{2}$ (Figure $4 \mathrm{j}$ and $\mathrm{k}$ ). They used a film of this material on the working electrode and demonstrated its rapid electron transfer rate in selected redox systems for glucose and dopamine sensing. Electrochemical systems based on $2 \mathrm{D} \mathrm{MoS}_{2}$ have also been incorporated for DNA sensing in nano molar ranges. ${ }^{79-80}$ Loo et al ${ }^{79}$ demonstrated DNA hybridization in electrochemical systems for sensing anomalies such as those in Alzheimer's disease. It is important to consider that like many other $2 \mathrm{D}$ materials with large and flat surface morphologies, affinity of $2 \mathrm{D}$ $\mathrm{MoS}_{2}$ towards single-stranded DNA is more than doublestranded DNA. Electrochemical sensing using $2 \mathrm{D} \mathrm{MoS}_{2}$ has also been employed for $\mathrm{H}_{2} \mathrm{O}_{2}$ sensing, a by-product of many oxidative cell reactions, with detection limits in nano molar ranges. ${ }^{81-82}$

\section{Electrodeless optical biosensors}

The PL of $2 \mathrm{D} \mathrm{MoS}_{2}$ can be quenched upon the immobilization of biomaterials onto its surface and/or interaction with them. Such changes in the PL have been associated with charge exchanges as well as electronic energy transfer (EET) and resonance energy transfer (RET) phenomena (Figure $5 \mathrm{a}$ ). ${ }^{23^{-25}}$ However, other effects such as changes of the surface roughness and permittivity can also alter PL in such biosensors and their role should be considered.

Another popular approach for optical sensing is the indirect PL quenching of biomaterials with tagged fluorophores (Figure $5 \mathrm{~b}$ ). Immobilization of such tagged biomaterials onto the surface of $2 \mathrm{D} \mathrm{MoS}$ may produce a reversible quenching and ${ }^{45}$ tagged aptamers have been engineered for specific biosensing applications according to this concept. ${ }^{83}$
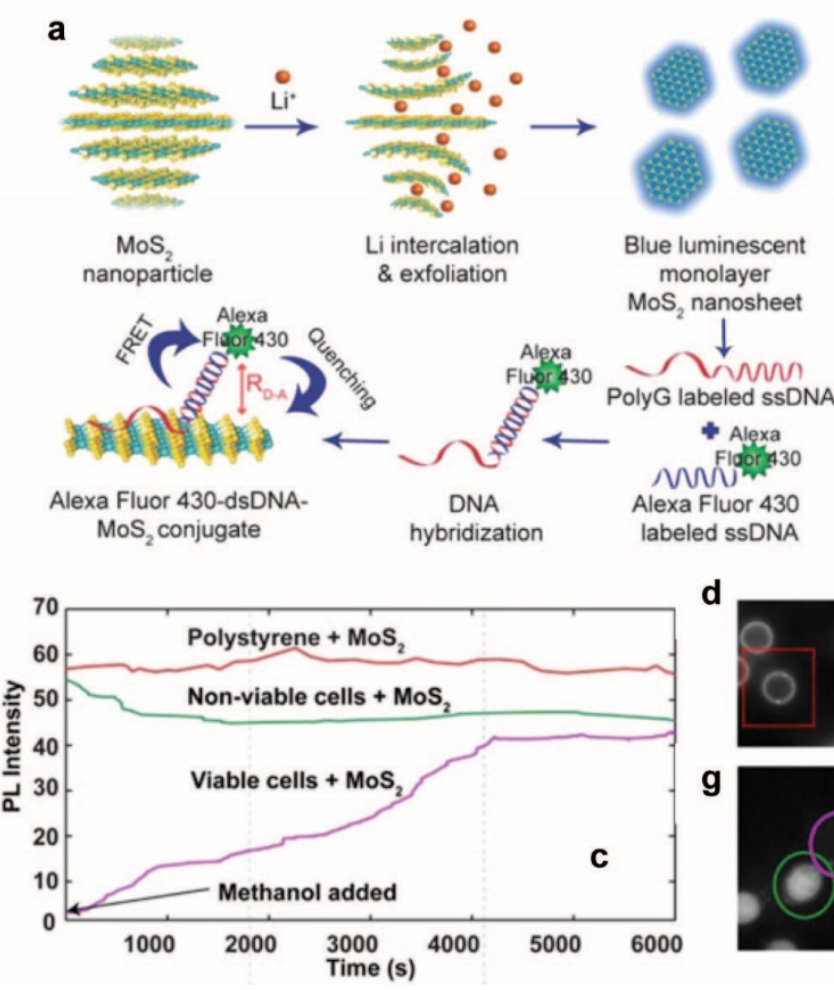

b
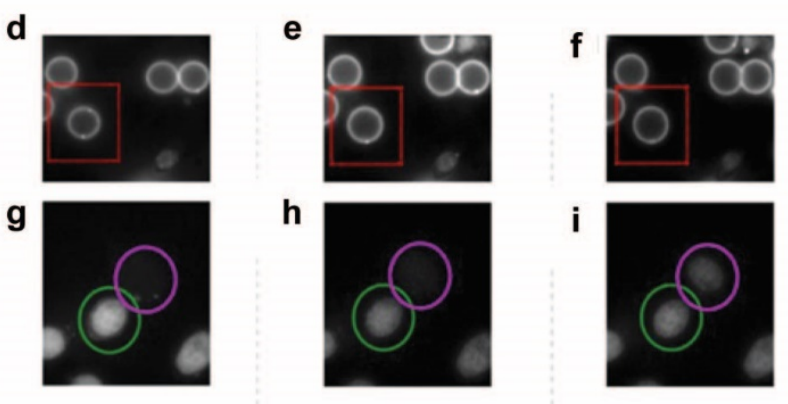

Figure 5. (a) Optical sensors based on the PL generated by $\mathrm{MoS}_{2}$ : Schematics for constructing the RET pair using the blue luminescent monolayered $\mathrm{MoS}_{2}$ nanosheets and the Alexa Fluor 430 which are separated by the dsDNA. Reprinted with permission from Ref 23. Copyright 2014 John Wiley \& Sons Publishing Company. (b) Incorporation of a tagged PL fluorophore: $2 \mathrm{D}$ MoS 2 adsorb dye-labeled single-stranded DNA probe via the van der Waals force and then quench the fluorescence of the dye. In contrast for double-stranded DNA, nucleobases are buried between the densely negatively charged helical phosphate backbones, and as a result their interaction with $\mathrm{MoS}_{2}$ is so weak. Reprinted with permission from Ref 45 . Copyright 2013 American Chemical Society. (c) PL response of quasi-2D MoS 2 nanoflake-coated polystyrene particles, non-viable and viable cells monitored over time for up to $6000 \mathrm{~s}$ after the addition of methanol. The corresponding fluorescent images of quasi-2 $\mathrm{D} \mathrm{MoS}_{2}$ nanoflake-coated polystyrene particles (red square) after (d) o, (e) 3000, and (f) $6000 \mathrm{~s}$, respectively. The corresponding fluorescent images of quasi-2D $\mathrm{MoS}_{2}$ nanoflake-coated nonviable (green circle) and viable cells (pink circle) after (g) o, (h) 300o, and (i) 6ooo s, respectively. Figure $5^{\mathrm{c}-\mathrm{i}}$ were reprinted with permission from Ref 21. Copyright 2014 American Chemical Society.

Very recently, it has been shown that plasmonics of highly doped 2D $\mathrm{MoS}_{2}$ can also be used for biosensing. ${ }^{84}$ Adhesion of the biomaterials onto the surface of $2 \mathrm{D}$ flakes changes the plasmon resonance peaks due to charge exchange and surface permittivity changes. Doping is a crit- ical step in producing the metallic $1 \mathrm{~T}$ phase of $\mathrm{MoS}_{2}$ that shifts the plasmon resonance peaks into the visible and near infrared light regions. Naturally, because of low carrier concentration of intrinsic $2 \mathrm{D} \mathrm{MoS}_{2}$, plasmon resonances appear in $\mathrm{THz},{ }^{85}$ which is still useful for biosensing 
but practically difficult in terms of accessibility to instruments for measurements in such a wavelength range.

\section{Reverse electroluminescent biosensors}

Intercalation of biologically important ions such as $\mathrm{H}^{+}$, $\mathrm{Li}^{+}, \mathrm{Na}^{+}$and $\mathrm{K}^{+}$can reduce the bandgap of $2 \mathrm{D} \mathrm{MoS}_{2}$ and eventually, at high intercalation concentration levels, transform $2 \mathrm{H} \mathrm{MoS}_{2}$ into the metallic $1 \mathrm{~T}$ phase. As such, these intercalation processes quench the PL at different levels. However, it is important to consider that always an electric field (via an applied voltage) is needed to assist in the procedure as the intercalation does not occur nationally. The electric field can be applied via external reference electrodes. ${ }^{21-22,} 84$ Interestingly, even the voltage across the bi-lipid membranes of a cell can provide a sufficient electric field for the intercalation to occur. The concept has been used for sensing glucose based on peroxidase-like activity on $2 \mathrm{D} \mathrm{MoS}_{2}$ (Figure $5 \mathrm{c}-\mathrm{i}$ ). ${ }^{21}$ Irradiation to IR or visible light can also assist in the intercalation process. ${ }^{86}$

\section{Other biosensing concepts}

In addition to the different types of biosensors based on pure $2 \mathrm{D} \mathrm{MoS}$, which were presented in the previous sections, this material has also been reported in composites for biosensing applications. Such biosensors have been developed based on composites with inorganic nanoparticles (both metals and metallic compounds), graphene, carbon nanotubes and a number of polymers. ${ }^{58,}{ }^{87}$ ${ }^{94}$ ENREF_76 To gain success, the composite components should be intelligently selected and well-engineered together with $2 \mathrm{D} \mathrm{MoS}$ in order to offer the enhancement for biosensing. It is suggested that synergy between $2 \mathrm{D}$ $\mathrm{MoS}_{2}$ and the added components, ${ }^{64}, 95$ the junction effects, ${ }^{96-100}$ catalytic properties ${ }^{101-102}$ and effective charge transfer ${ }^{103-104}$ can tune and enhance sensitivity and selectivity of such composite biosensors.

In biosensing, what is very important is the accurate control of the liquid flow, directing the bio analytes onto the surface of $2 \mathrm{D} \mathrm{MoS}$. The incorporation of microfluidics certainly help in achieving compatibility with the low dimensional $2 \mathrm{D} \mathrm{MoS}$ biosensing systems and their eventual incorporation into practical and low cost devices that can be deployed to the market. To achieve such goals, microfluidics for $\mathrm{PL}^{105}$ and field effect ${ }^{46,78}$ based biosensing using $2 \mathrm{D} \mathrm{MoS}_{2}$ have been shown.

Another recent application using $2 \mathrm{D} \mathrm{MoS}_{2}$ is in DNA sequencing. In such systems nanopores are formed into the plane of $2 \mathrm{D} \mathrm{MoS}_{2}$. The translocation of the DNA strands into these pores generates digital steps that correspond to the charge type on the strand. These $2 \mathrm{D} \mathrm{MoS}$ based nanoporous systems offer signal-to-noise ratios almost one order of magnitude superior to that of graphene. $^{106}$

It is also worth mentioning that $2 \mathrm{D} \mathrm{MoS}_{2}$ shows specific bio gas sensing properties due to the physisorption of selected gases onto its surface, which are associated to the dipole effect of the gas species. Biologically important gas species such as $\mathrm{NO},{ }^{107} \mathrm{NO}_{2},{ }^{108}$ and $\mathrm{NH}_{3}{ }^{109}$ as well as several organic vapors have been shown to physisorbed onto the surface of $2 \mathrm{D} \mathrm{MoS}_{2}$, with or without functionalized surfaces. ${ }^{110-111}$ Membranes with embedded $2 \mathrm{D} \mathrm{MoS}_{2}$ can also be used for increasing the selectivity to specific gas species. $^{112}$

\section{Conclusion and future directions}

A comprehensive review of what has so far been achieved and developed using $2 \mathrm{D} \mathrm{MoS}_{2}$ based biosensors was presented in this paper. We illustrated the key properties of $2 \mathrm{D} \mathrm{MoS}_{2}$ that provide unique opportunities for biosensing. We also demonstrated and analyzed the most recent advances based on biosensors that incorporate $2 \mathrm{D}$ $\mathrm{MoS}_{2}$. However, there are still plenty of biosensing concepts, structures and applications that can be potentially studied.

Investigations regarding $2 \mathrm{D} \mathrm{MoS}_{2}$ for enzymatic exchanges and other protein based systems should be expanded. Such biosensing reactions can also fully use the intercalation effects seen in $2 \mathrm{D} \mathrm{MoS}_{2}$.

A fundamental remaining issue is to understand more about the influences of the defects, dopants and lateral dimensions/thickness on the bio properties of $2 \mathrm{D} \mathrm{MoS}_{2}$. Knowing that the defects, kinks and edges introduce localized metallic regions and also changes in the electronic band diagram of $2 \mathrm{D} \mathrm{MoS}$, it is important to fundamentally understand them in order to more efficiency implement such properties for engineering efficient biosensors.

Making novel composites of $2 \mathrm{D} \mathrm{MoS}_{2}$ by incorporating yet to be investigated chemical components (e.g. metal oxides or other metallic compounds) and forming organic compounds with a variety of conductive and nonconductive polymers are all important topics that should be fully studied for biosensing. It is also worth mentioning the new concept of bio compatible inks for optical biosensing and bio surveillance should be considered. Due to remarkable optical properties and stability of $2 \mathrm{D}$ $\mathrm{MoS}_{2}$ flakes, they are ideal as the semiconducting or metallic component of bio inks.

So far only a limited number of templating platforms have been used for incorporating $2 \mathrm{D} \mathrm{MoS}_{2}$ in order to establish biosensors. Many other platforms can be used that are compatible with this material for which the incorporation of $2 \mathrm{D} \mathrm{MoS}$ may potentially result in exciting biosensing capabilities. This includes, but not limited to, surface plasmon resonance (SPR) and acoustic based templates. Advantageously, SPR systems are intrinsically compatible with layered materials. Many of the efficient SPR systems are covered with metallic gold as the surface plasmon confinement layer. In an alternative case, metallic $1 \mathrm{~T} \mathrm{MoS}_{2}$ can offer a biocompatible layer, also providing a great opportunity to obtain high Q SPR biosensors. 2D $\mathrm{MoS}_{2}$ can be potentially incorporated onto acoustic wave sensing templates such as surface acoustic wave (SAW) devices, standard cantilevers, and quartz crystal micro- 
balances. The surfaces of such acoustic transducers show high compatibility with $\mathrm{MoS}_{2}$. Additionally, $2 \mathrm{D} \mathrm{MoS}_{2}$ can accommodate both mass and charge within its layers and on its surface that can both produce electroacoustic responses.

${ }_{2} \mathrm{D} \mathrm{MoS}_{2}$ has also a relatively large strain limit and a high elastic modulus. ${ }^{113-114}$ As a result, this $2 \mathrm{D}$ material can be directly used for establishing the most sensitive cantilever biosensors with extraordinary low detection limits, possibly for the detection of single molecules. ${ }^{11-115}$ Very Recently, strong piezoelectric properties have been observed for odd layered $2 \mathrm{D} \mathrm{MoS}_{2}(2 \mathrm{D} \mathrm{MoS}$ made of $1,3,5, \ldots$ number of layers), which is the strongest for single layer $\mathrm{MoS}_{2}$ most sensitive cantilever biosensors with extraordinary low detection. ${ }^{115}$ As a result, the properties of odd layered $2 \mathrm{D} \mathrm{MoS}$ can be potentially employed to develop highly sensitive cantilever based mass detectors for biological components.

Thermal effect can also be used for bio calorimetry sensors. The thermal conductivity of multilayered $2 \mathrm{D} \mathrm{MoS}$ is extremely large along the planar directions and low in the direction normal to the planes. As a result, accurate structures for spatially confining and releasing heat from biosensing applications can be made based on $2 \mathrm{D} \mathrm{MoS}_{2}$.

Altogether $2 \mathrm{D} \mathrm{MoS}_{2}$ has still much more to offer to biosensing. It is expected that a large number of new biosensing concepts to be discovered and developed in the next decade to provide more opportunities for researchers working in relevant areas and also for industries via the rapid uptake of this material into biosensing systems.

\section{AUTHOR INFORMATION}

\section{Corresponding Author}

* Email: kourosh.kalantar@rmit.edu.au

\section{Author Contributions}

The manuscript was written through contributions of all authors.

\section{Funding Sources}

The authors acknowledge support from the Australian Research Council Discovery program (DP140100170).

\section{REFERENCES}

1. Balendhran, S.; Walia, S.; Nili, H.; Ou, J. Z.; Zhuiykov, S.; Kaner, R. B.; Sriram, S.; Bhaskaran, M.; Kalantar-zadeh, K. Two-Dimensional Molybdenum Trioxide and Dichalcogenides. Adv. Funct. Mater. 2013, 23, 3952-3970.

2. Jariwala, D.; Sangwan, V. K.; Lauhon, L. J.; Marks, T. J.; Hersam, M. C. Emerging Device Applications for Semiconducting Two-Dimensional Transition Metal Dichalcogenides. ACS Nano 2014, 8, 1102-1120.
3. Wang, Q. H.; Kalantar-zadeh, K.; Kis, A.; Coleman, J. N.; Strano, M. S. Electronics and Optoelectronics of Two-Dimensional Transition Metal Dichalcogenides. Nat. Nanotechnol. 2012, 7, 699-712.

4. Kalantar-zadeh, K.; Ou, J. Z.; Daeneke, T.; Strano, M. S.; Pumera, M.; Gras, S. L. Two-Dimensional Transition Metal Dichalcogenides in Biosystems. Adv. Funct. Mater. 2015, 25, 5086-5099.

5. Lee, C.; Yan, H.; Brus, L. E.; Heinz, T. F.; Hone, J.; Ryu, S. Anomalous Lattice Vibrations of Single- and Few-Layer $\mathrm{MoS}_{2}$. ACS Nano 2010, 4, 2695-270o.

6. Zhao, W.; Ribeiro, R. M.; Eda, G. Electronic Structure and Optical Signatures of Semiconducting Transition Metal Dichalcogenide Nanosheets. Accounts Chem. Res. 2015, 48, 91-99.

7. $\quad W u$, S.; Zeng, Z.; He, Q.; Wang, Z.; Wang, S. J.; Du, Y.; Yin, Z.; Sun, X.; Chen, W.; Zhang, H. Electrochemically Reduced Single-Layer $\mathrm{MoS}_{2}$ Nanosheets: Characterization, Properties, and Sensing Applications. Small 2012, 8, 2264-2270.

8. Sarkar, D.; Liu, W.; Xie, X.; Anselmo, A. C.; Mitragotri, S.; Banerjee, K. $\mathrm{MoS}_{2}$ Field-Effect Transistor for Next-Generation Label-Free Biosensors. ACS Nano 2014, 8, 3992-4003.

9. Stern, E.; Wagner, R.; Sigworth, F. J.; Breaker, R.; Fahmy, T. M.; Reed, M. A. Importance of the Debye Screening Length on Nanowire Field Effect Transistor Sensors. Nano Lett. 2007, 7, 3405-3409.

10. Chiu, C. W.; Huang, T. K.; Wang, Y. C.; Alamani, B. G.; Lin, J. J. Intercalation Strategies in Clay/Polymer Hybrids. Prog. Polym. Sci. 2014, 39, 443485 .

11. Choy, J.-H.; Choi, S.-J.; Oh, J.-M.; Park, T. Clay Minerals and Layered Double Hydroxides for Novel Biological Applications. App. Clay Sci. 2007, 36, 122-132. 12. Holm, R. H.; Kennepohl, P.; Solomon, E. I. Structural and Functional Aspects of Metal Sites in Biology. Chem. Rev. 1996, 96, 2239-2314.

13. Guo, Y.; Xu, K.; Wu, C.; Zhao, J.; Xie, Y. Surface Chemical-Modification for Engineering the Intrinsic Physical Properties of Inorganic Two-Dimensional Nanomaterials. Chem. Soc. Rev. 2015, 44, 637-646.

14. Addou, R.; McDonnell, S.; Barrera, D.; Guo, Z.; Azcatl, A.; Wang, J.; Zhu, H.; Hinkle, C. L.; QuevedoLopez, M.; Alshareef, H. N., et al. Impurities and Electronic Property Variations of Natural $\mathrm{MoS}_{2}$ Crystal Surfaces. ACS Nano 2015, 9, 9124-9133.

15. Butler, S. Z.; Hollen, S. M.; Cao, L.; Cui, Y.; Gupta, J. A.; Gutiérrez, H. R.; Heinz, T. F.; Hong, S. S.; Huang, J.; Ismach, A. F., et al. Progress, Challenges, and Opportunities in Two-Dimensional Materials Beyond Graphene. ACS Nano 2013, 7, 2898-2926.

16. Nicolosi, V.; Chhowalla, M.; Kanatzidis, M. G.; Strano, M. S.; Coleman, J. N. Liquid Exfoliation of Layered Materials. Science 2013, 340, 568-571.

17. Huang, X.; Yin, Z.; Wu, S.; Qi, X.; He, Q.; Zhang, Q.; Yan, Q.; Boey, F.; Zhang, H. Graphene- 
Based Materials: Synthesis, Characterization, Properties, and Applications. Small 2011, 7, 1876-1902.

18. Lin, Y.-C.; Dumcenco, D. O.; Huang, Y.-S.; Suenaga, K. Atomic Mechanism of the Semiconducting-To-Metallic Phase Transition in Single-Layered MoS2. Nat. Nanotechnol. 2014, 9, 391396.

19. Rao, C. N. R.; Ramakrishna Matte, H. S. S.; Maitra, U. Graphene Analogues of Inorganic Layered Materials. Angew. Chem. Int. Ed. 2013, 52, 13162-13185.

2o. Radisavljevic, B.; Radenovic, A.; Brivio, J.; Giacometti, V.; Kis, A. Single-Layer $\mathrm{MoS}_{2}$ Transistors. Nat. Nanotechnol. 2011, 6, 147-150.

21. Ou, J. Z.; Chrimes, A. F.; Wang, Y.; Tang, S. Y.; Strano, M. S.; Kalantar-zadeh, K. Ion-Driven Photoluminescence Modulation of Quasi-TwoDimensional $\mathrm{MoS}_{2}$ Nanoflakes for Applications in Biological Systems. Nano Lett. 2014, 14, 857-863.

22. Wang, Y.; Ou, J. Z.; Balendhran, S.; Chrimes, A. F.; Mortazavi, M.; Yao, D. D.; Field, M. R.; Latham, K.; Bansal, V.; Friend, J. R., et al. Electrochemical Control of Photoluminescence in Two-Dimensional $\mathrm{MoS}_{2}$ Nanoflakes. ACS Nano 2013, 7, 10083-10093.

23. Ha, H. D.; Han, D. J.; Choi, J. S.; Park, M.; Seo, T. S. Dual Role of Blue Luminescent $\mathrm{MoS}_{2}$ Quantum Dots in Fluorescence Resonance Energy Transfer Phenomenon. Small 2014, 10, 3858-3862.

24. Lin, T.; Zhong, L.; Song, Z.; Guo, L.; Wu, H.; Guo, Q.; Chen, Y.; Fu, F.; Chen, G. Visual Detection of Blood Glucose based on Peroxidase-Like Activity of $\mathrm{WS}_{2}$ Nanosheets. Biosens. Bioelectron. 2014, 62, 302307.

25. Wang, Y.; Ni, Y. Molybdenum Disulfide Quantum Dots as a Photoluminescence Sensing Platform for 2,4,6-Trinitrophenol Detection. Anal. Chem. 2014, 86, 7463-7470.

26. Mak, K.; Lee, C.; Hone, J.; Shan, J.; Heinz, T. Atomically Thin $\mathrm{MoS}_{2}$ : A New Direct-Gap Semiconductor. Phys. Rev. Lett. 2010, 105, 136805.

27. Li, H.; Zhang, Q.; Yap, C. C. R.; Tay, B. K.; Edwin, T. H. T.; Olivier, A.; Baillargeat, D. From Bulk to Monolayer $\mathrm{MoS}_{2}$ : Evolution of Raman Scattering. Adv. Funct. Mater. 2012, 22, 1385-139o.

28. Teo, W. Z.; Chng, E. L. K.; Sofer, Z.; Pumera, M. Cytotoxicity of Exfoliated Transition-Metal Dichalcogenides $\left(\mathrm{MoS}_{2}, \mathrm{WS}_{2}\right.$, and $\left.\mathrm{WSe}_{2}\right)$ is Lower Than That of Graphene and its Analogues. Chem. Eur. J. 2014, 20, 9627-9632.

29. Chhowalla, M.; Shin, H. S.; Eda, G.; Li, L.-J.; Loh, K. P.; Zhang, H. The Chemistry of TwoDimensional Layered Transition Metal Dichalcogenide Nanosheets. Nat. Chem. 2013, 5, 263-275.

30. Splendiani, A.; Sun, L.; Zhang, Y.; Li, T.; Kim, J.; Chim, C.-Y.; Galli, G.; Wang, F. Emerging Photoluminescence in Monolayer $\mathrm{MoS}_{2}$. Nano Lett. 2010, 10, 1271-1275.
31. Ganatra, R.; Zhang, Q. Few-Layer $\mathrm{MoS}_{2}$ : A Promising Layered Semiconductor. ACS Nano 2014, 8, 4074-4099.

32. Kaasbjerg, K.; Thygesen, K. S.; Jacobsen, K. W. Phonon-Limited Mobility in $n$-Type Single-Layer $\mathrm{MoS}_{2}$ from First Principles. Phys. Rev. B 2012, 85, 115317.

33. Wang, R.; Ruzicka, B. A.; Kumar, N.; Bellus, M. Z.; Chiu, H. Y.; Zhao, H. Ultrafast and Spatially Resolved Studies of Charge Carriers in Atomically Thin Molybdenum Disulfide. Phys. Rev. B 2012, 86, 045406.

34. Kadantsev, E. S.; Hawrylak, P. Electronic Structure of A Single $\mathrm{MoS}_{2}$ Monolayer. Solid State Commun. 2012, 152, 909-913.

35. Nguyen, E. P.; Carey, B. J.; Daeneke, T.; Ou, J. Z.; Latham, K.; Zhuiykov, S.; Kalantar-zadeh, K. Investigation of Two-Solvent Grinding-Assisted Liquid Phase Exfoliation of Layered $\mathrm{MoS}_{2}$. Chem. Mater. 2015, 27, 53-59.

36. Ataca, C.; Topsakal, M.; Aktürk, E.; Ciraci, S. A Comparative Study of Lattice Dynamics of Three- And Two-Dimensional $\mathrm{MoS}_{2}$. J. Phys. Chem. C 2011, 115, 16354-16361.

37. Zhao, Y.; Luo, X.; Li, H.; Zhang, J.; Araujo, P. T.; Gan, C. K.; Wu, J.; Zhang, H.; Quek, S. Y.; Dresselhaus, M. S., et al. Interlayer Breathing and Shear Modes in Few-Trilayer $\mathrm{MoS}_{2}$ and $\mathrm{WSe}_{2}$. Nano Lett. 2013, 13, 1007-1015.

38. Chakraborty, B.; Bera, A.; Muthu, D. V. S.; Bhowmick, S.; Waghmare, U. V.; Sood, A. K. Symmetry-Dependent Phonon Renormalization in Monolayer $\mathrm{MoS}_{2}$ Transistor. Phys. Rev. B 2012, 85, 161403.

39. Novoselov, K. S.; Jiang, D.; Schedin, F.; Booth, T. J.; Khotkevich, V. V.; Morozov, S. V.; Geim, A. K. Two-Dimensional Atomic Crystals. Proc.Natl. Acad. Sci. USA 2005, 102, 10451-10453.

40. Novoselov, K. S.; Jiang, D.; Schedin, F.; Booth, T. J.; Khotkevich, V. V.; Morozov, S. V.; Geim, A. K. Two-Dimensional Atomic Crystals. Proc. Natl. Acad. Sci. U.S.A. 2005, 102, 10451-10453.

41. Liu, K.-K.; Zhang, W.; Lee, Y.-H.; Lin, Y.-C.; Chang, M.-T.; Su, C.-Y.; Chang, C.-S.; Li, H.; Shi, Y.; Zhang, H., et al. Growth of Large-Area and Highly Crystalline $\mathrm{MoS}_{2}$ Thin Layers on Insulating Substrates. Nano Lett. 2012, 12, 1538-1544.

42. Zhan, Y.; Liu, Z.; Najmaei, S.; Ajayan, P. M.; Lou, J. Large-Area Vapor-Phase Growth and Characterization of $\mathrm{MoS}_{2}$ Atomic Layers on a $\mathrm{SiO}_{2}$ Substrate. Small 2012, 8, 966-971.

43. Balendhran, S.; Ou, J. Z.; Bhaskaran, M.; Sriram, S.; Ippolito, S.; Vasic, Z.; Kats, E.; Bhargava, S.; Zhuiykov, S.; Kalantar-zadeh, K. Atomically Thin Layers of $\mathrm{MoS}_{2}$ via A Two Step Thermal EvaporationExfoliation Method. Nanoscale 2012, 4, 461-466.

44. Weber, T.; Muijsers, J. C.; van Wolput, J. H. M. C.; Verhagen, C. P. J.; Niemantsverdriet, J. W. Basic Reaction Steps in the Sulfidation of Crystalline $\mathrm{MoO}_{3}$ 
to $\mathrm{MoS}_{2}$, As Studied by X-ray Photoelectron and Infrared Emission Spectroscopy. J. Phys. Chem. 1996, 100, 14144-14150.

45. Zhu, C.; Zeng, Z.; Li, H.; Li, F.; Fan, C.; Zhang, H. Single-Layer $\mathrm{MoS}_{2}$-Based Nanoprobes for Homogeneous Detection of Biomolecules. J. Am. Chem. Soc. 2013, 135, 5998-6oo1.

46. Wang, L.; Wang, Y.; Wong, J. I.; Palacios, T.; Kong, J.; Yang, H. Y. Functionalized $\mathrm{MoS}_{2}$ NanosheetBased Field-Effect Biosensor for Label-Free Sensitive Detection of Cancer Marker Proteins in Solution. Small 2014, 10, 1101-1105.

47. Chrimes, A. F.; Khoshmanesh, K.; Stoddart, P. R.; Mitchell, A.; Kalantar-zadeh, K. Microfluidics and Raman Microscopy: Current Applications and Future Challenges. Chem. Soc. Rev. 2013, 42, 5880-5906.

48. Benavente, E.; Santa Ana, M. A.; Mendizábal, F.; González, G. Intercalation Chemistry of Molybdenum Disulfide. Coord. Chem. Rev. 2002, 224, 87-109.

49. Benavente, E.; González, G. Microwave Activated Lithium Intercalation in Transition Metal Sulfides. Mater. Res. Bull. 1997, 32, 709-717.

5o. Zeng, Z.; Yin, Z.; Huang, X.; Li, H.; He, Q.; Lu, G.; Boey, F.; Zhang, H. Single-Layer Semiconducting Nanosheets: High-Yield Preparation and Device Fabrication. Angew. Chem. Int. Ed. 2011, 50, 11093-11097. 51. O'Neill, A.; Khan, U.; Coleman, J. N. Preparation of High Concentration Dispersions of Exfoliated $\mathrm{MoS}_{2}$ with Increased Flake Size. Chem. Mater. 2012, 24, 2414-2421.

52. Coleman, J. N.; Lotya, M.; O'Neill, A.; Bergin, S. D.; King, P. J.; Khan, U.; Young, K.; Gaucher, A.; De, S.; Smith, R. J., et al. Two-Dimensional Nanosheets Produced by Liquid Exfoliation of Layered Materials. Science 2011, 331, 568-571.

53. Smith, R. J.; King, P. J.; Lotya, M.; Wirtz, C.; Khan, U.; De, S.; O'Neill, A.; Duesberg, G. S.; Grunlan, J. C.; Moriarty, G., et al. Large-Scale Exfoliation of Inorganic Layered Compounds in Aqueous Surfactant Solutions. Adv. Mater. 2011, 23, 3944-3948.

54. Ataca, C.; Ciraci, S. Functionalization of Single-Layer $\mathrm{MoS}_{2}$ Honeycomb Structures. J. Phys. Chem. C 2011, 115, 13303-13311.

55. Yu, X.; Prévot, M. S.; Sivula, K. Multiflake Thin Film Electronic Devices of Solution Processed 2D $\mathrm{Mos}_{2}$ Enabled by Sonopolymer Assisted Exfoliation and Surface Modification. Chem. Mater. 2014, 26, 58925899 .

56. Najmaei, S.; Yuan, J.; Zhang, J.; Ajayan, P.; Lou, J. Synthesis and Defect Investigation of TwoDimensional Molybdenum Disulfide Atomic Layers. Acc. Chem. Res. 2015, 48, 31-40.

57. Eda, G.; Fujita, T.; Yamaguchi, H.; Voiry, D.; Chen, M.; Chhowalla, M. Coherent Atomic and Electronic Heterostructures of Single-Layer $\mathrm{MoS}_{2}$. ACS Nano 2012, 6, 7311-7317.
58. Tan, C.; Zhang, H. Two-Dimensional Transition Metal Dichalcogenide Nanosheet-based Composites. Chem. Soc. Rev. 2015, 44, 2713-2731.

59. Voiry, D.; Goswami, A.; Kappera, R.; SilvaCecilia de Carvalho Castro, e.; Kaplan, D.; Fujita, T.; Chen, M.; Asefa, T.; Chhowalla, M. Covalent Functionalization of Monolayered Transition Metal Dichalcogenides by Phase Engineering. Nat. Chem. 2015, 7, 45-49.

6o. Chou, S. S.; De, M.; Kim, J.; Byun, S.; Dykstra, C.; Yu, J.; Huang, J.; Dravid, V. P. Ligand Conjugation of Chemically Exfoliated $\mathrm{MoS}_{2}$. J. Am. Chem. Soc. 2013, 135, 4584-4587.

61. Liu, T.; Wang, C.; Gu, X.; Gong, H.; Cheng, L.; Shi, X.; Feng, L.; Sun, B.; Liu, Z. Drug Delivery with PEGylated $\mathrm{MoS}_{2}$ Nano-sheets for Combined Photothermal and Chemotherapy of Cancer. Adv. Mater. 2014, 26, 3433-3440.

62. Coehoorn, R.; Haas, C.; Dijkstra, J.; Flipse, C.; de Groot, R.; Wold, A. Electronic Structure of $\mathrm{MoSe}_{2}$ $\mathrm{MoS}_{2}$, and $\mathrm{WSe}_{2}$. I. Band-Structure Calculations and Photoelectron Spectroscopy. Phys. Rev. B 1987, 35, 6195-6202.

63. Moore, S. E.; Lunsford, J. H. The Role of Hydrogen in the Reaction of Water with Surface Carbon to Form Methane. J. Catal. 1982, 77, 297-300.

64. Stephenson, T.; Li, Z.; Olsen, B.; Mitlin, D. Lithium Ion Battery Applications of Molybdenum Disulfide $\left(\mathrm{MoS}_{2}\right)$ Nanocomposites. Energy Environ. Sci. 2014, 7, 209-231.

65. Bhandavat, R.; David, L.; Singh, G. Synthesis of Surface-Functionalized $\mathrm{WS}_{2} \quad$ Nanosheets and Performance as Li-Ion Battery Anodes. J. Phys. Chem. Lett. 2012, 3, 1523-1530.

66. Loo, A. H.; Bonanni, A.; Sofer, Z.; Pumera, M. Exfoliated Transition Metal Dichalcogenides $\left(\mathrm{MoS}_{2}\right.$, $\mathrm{MoSe}_{2}, \mathrm{WS}_{2}, \mathrm{WSe}_{2}$ ): An Electrochemical Impedance Spectroscopic Investigation. Electrochem. Commun. 2015, 50, 39-42.

67. Bissessur, R.; Schindler, J. L.; Kannewurf, C. R.; Kanatzidis, M. Nanoscale Composites Formed by Encapsulation of Polymers in $\mathrm{MoS}_{2}$. From Conjugated Polymers to Plastics. Detection of Metal to Insulator Transition. Mol. Cryst. Liq. Crys. A 1994, 245, 249-254.

68. Lemmon, J. P.; Wu, J.; Oriakhi, C.; Lerner, M. M. Preparation of Nanocomposites Containing Poly(Ethylene Oxide) and Layered Solids. Electrochim. Acta 1995, 40, 2245-2249.

69. Yang, Y.; Liu, T.; Cheng, L.; Song, G.; Liu, Z.; Chen, M. $\mathrm{MoS}_{2}$-Based Nanoprobes for Detection of Silver Ions in Aqueous Solutions and Bacteria. ACS Appl. Mater. Interfaces 2015, 7, 7526-7533.

7o. Wang, N.; Wei, F.; Qi, Y.; Li, H.; Lu, X.; Zhao, G.; Xu, Q. Synthesis of Strongly Fluorescent Molybdenum Disulfide Nanosheets for Cell-Targeted Labeling. ACS Appl. Mater. Interfaces 2014, 6, 1988819894. 
71. Chng, E. L. K.; Sofer, Z.; Pumera, M. $\mathrm{MoS}_{2}$ Exhibits Stronger Toxicity with Increased Exfoliation. Nanoscale 2014, 6, 14412-14418.

72. Ajayan, P. M.; Tour, J. M. Materials Science: Nanotube Composites. Nature 2007, 447, 1066-1068.

73. Chen, Y.; Tan, C.; Zhang, H.; Wang, L. TwoDimensional Graphene Analogues for Biomedical Applications. Chem. Soc. Rev. 2015.

74. Pumera, M.; Loo, A. H. Layered TransitionMetal Dichalcogenides $\left(\mathrm{MoS}_{2}\right.$ and $\left.\mathrm{WS}_{2}\right)$ for Sensing and Biosensing. TrAC-Trend Anal. Chem. 2014, 61, 4953 .

75. Lee, J.; Dak, P.; Lee, Y.; Park, H.; Choi, W.; Alam, M. A.; Kim, S. Two-Dimensional Layered $\mathrm{MoS}_{2}$ Biosensors Enable Highly Sensitive Detection of Biomolecules. Sci. Rep. 2014, 4, 7352.

76. Nam, H.; Oh, B.-R.; Chen, P.; Yoon, J. S.; Wi, S.; Chen, M.; Kurabayashi, K.; Liang, X. Two Different Device Physics Principles for Operating $\mathrm{MoS}_{2}$ Transistor Biosensors with Femtomolar-Level Detection Limits. App. Phys. Lett. 2015, 107, 012105.

77. Lee, D. W.; Lee, J.; Sohn, I. Y.; Kim, B. Y.; Son, Y. M.; Bark, H.; Jung, J.; Choi, M.; Kim, T. H.; Lee, C., et al. Field-Effect Transistor with A Chemically Synthesized $\mathrm{MoS}_{2}$ Sensing Channel for Label-Free and Highly Sensitive Electrical Detection of DNA Hybridization. Nano Res. 2015, 8, 2340-2350.

78. Nam, H.; Oh, B.-R.; Chen, P.; Chen, M.; Wi, S.; Wan, W.; Kurabayashi, K.; Liang, X. Multiple $\mathrm{MoS}_{2}$ Transistors for Sensing Molecule Interaction Kinetics. Sci. Rep. 2015, 5, 10546.

79. Loo, A. H.; Bonanni, A.; Ambrosi, A.; Pumera, M. Molybdenum Disulfide $\left(\mathrm{MoS}_{2}\right)$ Nanoflakes as Inherently Electroactive Labels for DNA Hybridization Detection. Nanoscale 2014, 6, 11971-11975.

8o. Loo, A. H.; Bonanni, A.; Sofer, Z.; Pumera, M. Transitional Metal/Chalcogen Dependant Interactions of Hairpin DNA with Transition Metal Dichalcogenides, $\mathrm{MX}_{2}$. ChemPhysChem 2015, 16, 23042306.

81. Wang, T.; Zhu, R.; Zhuo, J.; Zhu, Z.; Shao, Y.; Li, M. Direct Detection of DNA below ppb Level based on Thionin-Functionalized Layered $\mathrm{MoS}_{2}$ Electrochemical Sensors. Anal. Chem. 2014, 86, 1206412069.

82. Wang, G.-X.; Bao, W.-J.; Wang, J.; Lu, Q.-Q.; Xia, X.-H. Immobilization and Catalytic Activity of Horseradish Peroxidase on Molybdenum Disulfide Nanosheets Modified Electrode. Electrochem. Commun. 2013, 35, 146-148.

83. Ge, J.; Ou, E.-C.; Yu, R.-Q.; Chu, X. A Novel Aptameric Nanobiosensor based on the SelfAssembled DNA-MoS ${ }_{2}$ Nanosheet Architecture for Biomolecule Detection. J. Phys. Chem. B 2014, 2, 625628.

84. Wang, Y.; Ou, J. Z.; Chrimes, A. F.; Carey, B. J.; Daeneke, T.; Alsaif, M. M. Y. A.; Mortazavi, M.;
Zhuiykov, S.; Medhekar, N.; Bhaskaran, M., et al. Plasmon Resonances of Highly Doped TwoDimensional $\mathrm{MoS}_{2}$. Nano Lett. 2015, 15, 883-890.

85. Scholz, A.; Stauber, T.; Schliemann, J. Plasmons and Screening in a Monolayer of $\mathrm{MoS}_{2}$. Phys. Rev. B 2013, 88, 035135.

86. Fan, X.; Xu, P.; Zhou, D.; Sun, Y.; Li, Y. C.; Nguyen, M. A. T.; Terrones, M.; Mallouk, T. E. Fast and Efficient Preparation of Exfoliated $2 \mathrm{H} \quad \mathrm{MoS}_{2}$ Nanosheets by Sonication-Assisted Lithium Intercalation and Infrared Laser-Induced $1 \mathrm{~T}$ to $2 \mathrm{H}$ Phase Reversion. Nano Lett. 2015, 15, 5956-5960.

87. Su, S.; Sun, H.; Xu, F.; Yuwen, L.; Wang, L. Highly Sensitive and Selective Determination of Dopamine in the Presence of Ascorbic Acid Using Gold Nanoparticles-Decorated $\mathrm{MoS}_{2}$ Nanosheets Modified Electrode. Electroanal. 2013, 25, 2523-2529.

88. Liu, Y.-M.; Zhou, M.; Liu, Y.-Y.; Shi, G.-F.; Zhang, J.-J.; Cao, J.-T.; Huang, K.-J.; Chen, Y.-H. Fabrication of Electrochemiluminescence Aptasensor based on In Situ Growth of Gold Nanoparticles on Layered Molybdenum DisulfidefFor Sensitive Detection of Platelet-Derived Growth Factor-BB. RSC Adv. 2014, 4, 22888-22893.

89. Huang, J.; Dong, Z.; Li, Y.; Li, J.; Tang, W.; Yang, H.; Wang, J.; Bao, Y.; Jin, J.; Li, R. $\mathrm{MoS}_{2}$ Nanosheet Functionalized with $\mathrm{Cu}$ Nanoparticles and Its Application for Glucose Detection. Mater. Res. Bull. 2013, 48, 4544-4547.

9o. Huang, K.-J.; Wang, L.; Li, J.; Liu, Y.-M. Electrochemical Sensing based on Layered $\mathrm{MoS}_{2}-$ Graphene Composites. Sensor Actuat. B-Chem. 2013, 178, 671-677.

91. Huang, K.-J.; Liu, Y.-J.; Wang, H.-B.; Wang, Y.Y.; Liu, Y.-M. Sub-Femtomolar DNA Detection based on Layered Molybdenum Disulfide/Multi-Walled Carbon Nanotube Composites, Au Nanoparticle and Enzyme Multiple Signal Amplification. Biosens. Bioelectron. 2014, 55, 195-202.

92. Feng, Q.; Duan, K.; Ye, X.; Lu, D.; Du, Y.; Wang, C. A Novel Way for Detection of Eugenol via Poly (Diallyldimethylammonium Chloride) Functionalized Graphene- $\mathrm{MoS}_{2}$ Nano-Flower Fabricated Electrochemical Sensor. Sensor Actuat. BChem. 2014, 192, 1-8.

93. Wang, X.; Deng, W.; Shen, L.; Yan, M.; Ge, S.; Yu, J. A Sensitive Quenched Electrochemiluminescent DNA Sensor based on the Catalytic Activity of Gold Nanoparticle Functionalized $\mathrm{MoS}_{2}$. New J. Chem. 2015, 39, 8100-8107.

94. Daeneke, T.; Carey, B. J.; Chrimes, A. F.; Ou, J. Z.; Lau, D. W. M.; Gibson, B. C.; Bhaskaran, M.; Kalantar-Zadeh, K. Light Driven Growth of Silver Nanoplatelets on $2 \mathrm{D} \mathrm{MoS}$ Nanosheet Templates. J. Mater. Chem. C 2015, 3, 4771-4778.

95. Wang, S.; Jiang, X.; Zheng, H.; Wu, H.; Kim, S. J.; Feng, C. Solvothermal Synthesis of $\mathrm{MoS}_{2} /$ Carbon 
Nanotube Composites with Improved Electrochemical Performance for Lithium Ion Batteries. Nanosci. Nanotechnol. Lett. 2012, 4, 378-383.

96. Farmanbar, M.; Brocks, G. Controlling the Schottky Barrier at $\mathrm{MoS}_{2}$ /Metal Contacts by Inserting A BN Monolayer. Phys. Rev. B 2015, 91, 161304.

97. Gong, C.; Colombo, L.; Wallace, R. M.; Cho, K. The Unusual Mechanism of Partial Fermi Level Pinning at Metal-MoS ${ }_{2}$ Interfaces. Nano Lett. 2014, 14, 1714-1720.

98. Kappera, R.; Voiry, D.; Yalcin, S. E.; Branch, B.; Gupta, G.; Mohite, A. D.; Chhowalla, M. PhaseEngineered Low-Resistance ContactsfFor Ultrathin $\mathrm{MoS}_{2}$ Transistors. Nat. Mater. 2014, 13, 1128-1134.

99. Kwak, J. Y.; Hwang, J.; Calderon, B.; Alsalman, H.; Munoz, N.; Schutter, B.; Spencer, M. G. Electrical Characteristics of Multilayer $\mathrm{MoS}_{2}$ FETs with $\mathrm{MoS}_{2} /$ Graphene Heterojunction Contacts. Nano Lett. 2014, 14, 4511-4516.

10o. Walia, S.; Balendhran, S.; Wang, Y.; Ab Kadir, R.; Sabirin Zoolfakar, A.; Atkin, P.; Zhen Ou, J.; Sriram, S.; Kalantar-zadeh, K.; Bhaskaran, M. Characterization of Metal Contacts for Two-Dimensional $\mathrm{MoS}_{2}$ Nanoflakes. App. Phys. Lett. 2013, 103, 232105.

101. Karunadasa, H. I.; Montalvo, E.; Sun, Y.; Majda, M.; Long, J. R.; Chang, C. J. A Molecular $\mathrm{MoS}_{2}$ Edge Site Mimic for Catalytic Hydrogen Generation. Science 2012, 335, 698-702.

102. Li, Y.; Wang, H.; Xie, L.; Liang, Y.; Hong, G.; Dai, H. $\mathrm{MoS}_{2}$ Nanoparticles Grown on Graphene: An Advanced Catalyst for the Hydrogen Evolution Reaction. J. Am. Chem. Soc. 2011, 133, 7296-7299.

103. Fang, H.; Battaglia, C.; Carraro, C.; Nemsak, S.; Ozdol, B.; Kang, J. S.; Bechtel, H. A.; Desai, S. B.; Kronast, F.; Unal, A. A., et al. Strong Interlayer Coupling in Van Der Waals Heterostructures Built from Single-Layer Chalcogenides. Proc. Natl. Acad. Sci. U.S.A. 2014, 111, 6198-6202.

104. Wang, J. Z.; Lu, L.; Lotya, M.; Coleman, J. N.; Chou, S. L.; Liu, H. K.; Minett, A. I.; Chen, J. Development of $\mathrm{MoS}_{2}$-CNT Composite Thin Film from Layered $\mathrm{MoS}_{2}$ for Lithium Batteries. Adv. Energy Mater. 2013, 3, 798-805.

105. Huang, Y.; Shi, Y.; Yang, H. Y.; Ai, Y. A Novel Single-Layered $\mathrm{MoS}_{2}$ Nanosheet based Microfluidic Biosensor for Ultrasensitive Detection of DNA. Nanoscale 2015, 7, 2245-2249.

106. Liu, K.; Feng, J.; Kis, A.; Radenovic, A. Atomically Thin Molybdenum Disulfide Nanopores with High Sensitivity for DNA Translocation. ACS Nano 2014, 8, 2504-2511.

107. Li, H.; Yin, Z.; He, Q.; Li, H.; Huang, X.; Lu, G.; Fam, D. W. H.; Tok, A. I. Y.; Zhang, Q.; Zhang, H. Fabrication of Single- and Multilayer MoS2 Film-Based Field-Effect Transistors for Sensing $\mathrm{NO}$ at Room Temperature. Small 2012, 8, 63-67.
108. Yue, Q.; Shao, Z.; Chang, S.; Li, J. Adsorption of Gas Molecules on Monolayer $\mathrm{MoS}_{2}$ and Effect of Applied Electric Field. Nanoscale Res Lett 2013, 8, 1-7.

109. Late, D. J.; Huang, Y.-K.; Liu, B.; Acharya, J.; Shirodkar, S. N.; Luo, J.; Yan, A.; Charles, D.; Waghmare, U. V.; Dravid, V. P., et al. Sensing Behavior of Atomically Thin-Layered $\mathrm{MoS}_{2}$ Transistors. ACS Nano 2013, 7, 4879-4891.

110. Huo, N.; Yang, S.; Wei, Z.; Li, S.-S.; Xia, J.-B.; Li, J. Photoresponsive and Gas Sensing Field-Effect Transistors based on Multilayer $\mathrm{WS}_{2}$ Nanoflakes. Sci. Rep. 2014, 4, 5209.

111. Perkins, F. K.; Friedman, A. L.; Cobas, E.; Campbell, P. M.; Jernigan, G. G.; Jonker, B. T. Chemical Vapor Sensing with Monolayer $\mathrm{MoS}_{2}$. Nano Lett. 2013, $13,668-673$.

112. Berean, K. J.; Ou, J. Z.; Daeneke, T.; Carey, B. J.; Nguyen, E. P.; Wang, Y.; Russo, S. P.; Kaner, R. B.; Kalantar-zadeh, K. $2 \mathrm{D} \mathrm{MoS}_{2}$ PDMS Nanocomposites for $\mathrm{NO}_{2}$ Separation. Small 2015, DOI: 10.1002/smll.201501129.

113. Castellanos-Gomez, A.; Poot, M.; Steele, G. A.; van der Zant, H. S. J.; Agraït, N.; Rubio-Bollinger, G. Elastic Properties of Freely Suspended $\mathrm{MoS}_{2}$ Nanosheets. Adv. Mater. 2012, 24, 772-775.

114. Castellanos-Gomez, A.; van Leeuwen, R.; Buscema, M.; van der Zant, H. S. J.; Steele, G. A.; Venstra, W. J. Single-Layer $\mathrm{MoS}_{2}$ Mechanical Resonators. Adv. Mater. 2013, 25, 6719-6723.

115. Wu, W.; Wang, L.; Li, Y.; Zhang, F.; Lin, L.; Niu, S.; Chenet, D.; Zhang, X.; Hao, Y.; Heinz, T. F., et al. Piezoelectricity of Single-Atomic-Layer $\mathrm{MoS}_{2}$ for Energy Conversion and Piezotronics. Nature 2014, 514, 470-474. 